\title{
Modeling of SRS Aluminum- clad Spent Nuclear Fuel in Standard DOE Sealed Canisters
}

Alexander W Abboud

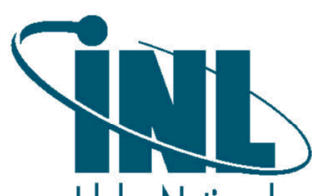

Idaho National

Laboratory 


\section{DISCLAIMER}

This information was prepared as an account of work sponsored by an agency of the U.S. Government. Neither the U.S. Government nor any agency thereof, nor any of their employees, makes any warranty, expressed or implied, or assumes any legal liability or responsibility for the accuracy, completeness, or usefulness, of any information, apparatus, product, or process disclosed, or represents that its use would not infringe privately owned rights. References herein to any specific commercial product, process, or service by trade name, trade mark, manufacturer, or otherwise, does not necessarily constitute or imply its endorsement, recommendation, or favoring by the U.S. Government or any agency thereof. The views and opinions of authors expressed herein do not necessarily state or reflect those of the U.S. Government or any agency thereof. 
INL EXT-20-57893

Revision 0

\section{Modeling of SRS Aluminum-clad Spent Nuclear Fuel in Standard DOE Sealed Canisters}

Alexander W Abboud

March 2020

Idaho National Laboratory

Idaho Falls, Idaho 83415

http://www.inl.gov

Prepared for the

U.S. Department of Energy

Office of Environmental Management

Under DOE Idaho Operations Office

Contract DE-AC07-05ID14517 
Page intentionally left blank 


\section{SUMMARY}

At the Savannah River Site (SRS), approximately 7 MTHM of aluminum-clad spent nuclear fuel is currently in wet storage at L-Basin. Current baseline planning is to process the spent nuclear fuel at HCanyon. A potential alternative to $\mathrm{H}$-Canyon processing is to dry the fuel and package in a road ready configuration using a multi-purpose canister, such as the DOE standard canister. To understand the potential for gas generation in the canisters, first the thermal and dose rate profiles need to be resolved. A computational fluid dynamics model is built to resolve the 50-year trend for the thermal profile, and MCNP is used to resolve the decay heat and surface dose rate of the fuel. This report will focus on a few fuel types, which should bound all other fuel stored at SRS. These consist of the reference fuel assembly, the MURR fuel and the HFIR fuel. These bound a hypothetical maximum scenario for MTR box fuel, a maximum for decay heat in an assembly, and a maximum for the aluminum surface area, respectively. The geometry for the packages was created from DOE specifications for storage of each of the fuels. As long as the minimum time from reactor discharge to sealed storage is 3 years, then the highest temperatures which occur within the sealed canisters do not exceed $100^{\circ} \mathrm{C}$ for all scenarios considered here. If the minimum time from reactor discharge to sealed storage is 10 years, the maximum temperature does not exceed $50^{\circ} \mathrm{C}$ for all the scenarios considered. In the geometry considered, while the HFIR fuel has a large surface area, the packaging configuration leaves large void areas, such that the aluminum surface to free volume ratio is about 30\% less than an ATR or MURR packaging configuration. Due to the highest surface area to volume ratio for a loaded DOE standard canister, and a high maximum temperature for the aluminum surface, the MURR loaded DOE standard canister should provide a bounding case for all aluminum-clad fuel currently stored at SRS. 


\section{ACKNOWLEDGEMENTS}

This work was funded by the U.S. Department of Energy Environmental Management office. This work was performed by Battelle Energy Alliance, LLC, under DOE Idaho Operations Contract DE-AC07-05ID14517 and made use of the resources of the High Performance Computing Center at Idaho National Laboratory which is supported by the Office of Nuclear Energy of the U.S. DOE and the Nuclear Science User Facilities. 
Page intentionally left blank 


\section{CONTENTS}

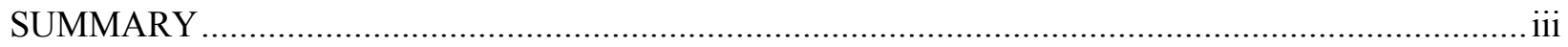

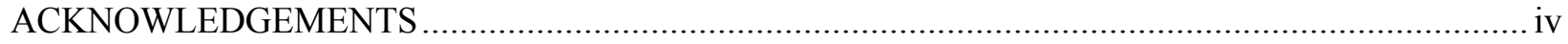

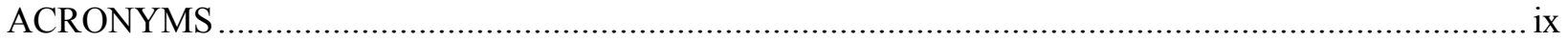

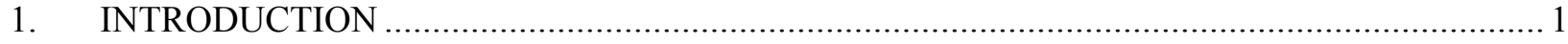

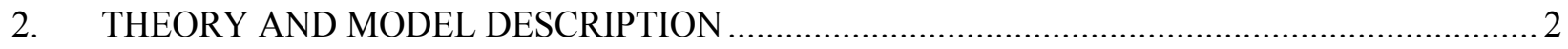

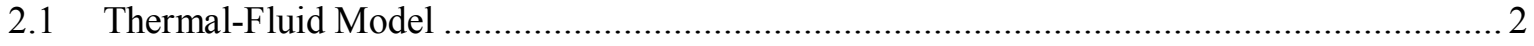

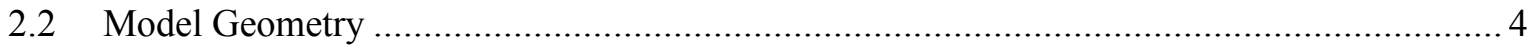

2.3 Thermal Decay Heat and Ambient Conditions .......................................................... 7

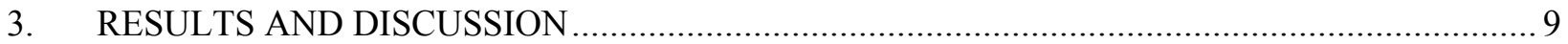

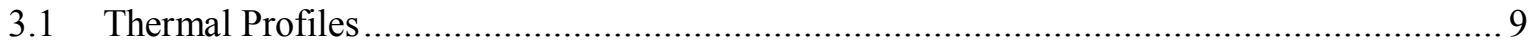

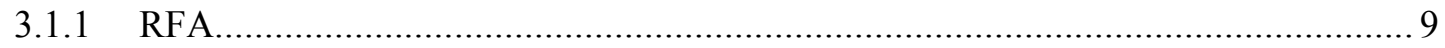

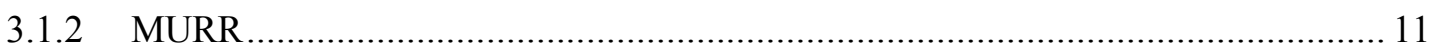

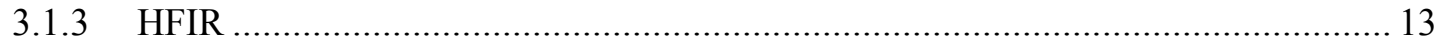

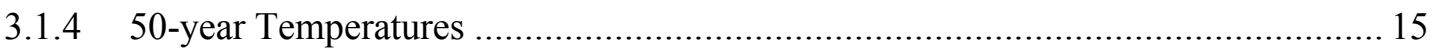

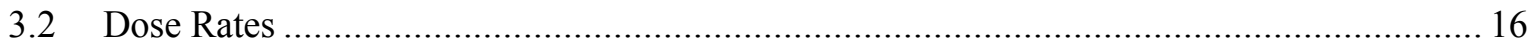

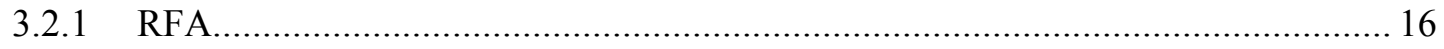

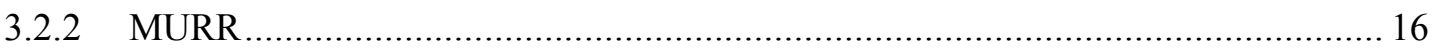

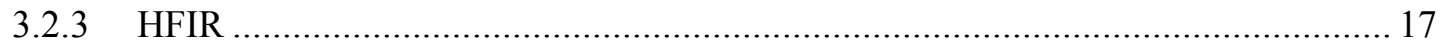

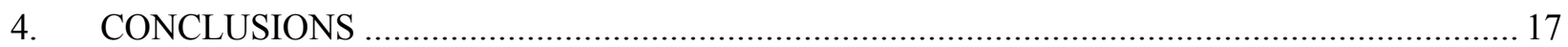

Appendix A MURR and HFIR Decay Heat and Dose Rate Calculations ...........................................22

\section{FIGURES}

Figure 1. CAD model for (a) loaded MURR canister, (b) modified Type 1a basket, (c) MURR fuel assembly, and (d) domain mesh slice.

Figure 2. CAD model for (a) loaded RFA canister, (b) loaded RFA-14 canister, (c) 14-slot basket (d) RFA fuel assembly, (e) Type-1a loading domain mesh slice, and (f) RFA-14 loading domain mesh slice.

Figure 3. CAD model for (a) loaded HFIR-inner canister, (b) modified Type 6a basket, (c) HFIRinner fuel assembly, and (d) domain mesh slice.....

Figure 4. CAD model for (a) loaded HFIR-outer canister, (b) modified Type $6 \mathrm{~b}$ basket, (c) HFIRouter fuel assembly, and (d) domain mesh slice.

Figure 5. Thermocouple measurements over 1 year in the INL CPP-603 facility for (a) one-hour intervals, (b) 12-hour and weekly intervals, and (c) maximum and minimum difference from average... 
Figure 6. Temperature contours of RFA for bottom, middle and top bucket for (a-c) Low Q, 18" (d-f) Base Q 18”, (g-i) Hi Q 18”, , (j-1) Low Q 24”, (m-o) Base Q 24”, (p-r) High Q 24”...

Figure 7. Velocity streamlines of RFA loaded canister for (a) Low Q 18”, (b) base 18”, (c) High Q 18", (d) Low Q 24", (e) Base 24" and (f) High Q 24".

Figure 8. Temperature contours of MURR loaded canister for bottom, middle and top bucket for (a-c) Low Q, 18" (d-f) Base Q 18", (g-i) Hi Q 18".

Figure 9. Velocity streamlines of a MURR loaded canister for (a-c) Low Q, 18” (d-f) Base Q 18", (g-i) Hi Q 18".

Figure 10. Temperature contours of HFIR-inner for bottom, middle and top assembly for (a-c) Low Q, 18" (d-f) Base Q 18", (g-i) Hi Q 18".....

Figure 11. Velocity streamlines for the HFIR inner loaded canister (a) Low Q, (b) Base Q, and (c) Hi Q.

Figure 12. Temperature contours of HFIR-outer for bottom, middle and top assembly for (a-c) Low Q, 18" (d-f) Base Q 18", (g-i) Hi Q 18"......

Figure 13. Streamlines of the velocity in the HFIR-outer loaded canister for (a-c) Low Q, 18" (df) Base Q 18", (g-i) Hi Q 18". 15

Figure 14. 50-year average temperatures, for (a) RFA in Type-1a basket, (b) RFA in modified 14slot basket, (c) MURR in Type 1a basket, (d) HFIR inner in Type 6a basket and (e) HFIR outer in Type $6 \mathrm{~b}$ basket. 16

Figure 15. Dose rate contour profile for standard DOE canister with MURR fuel loaded. .24

Figure 16. (a) Homogenized profile for DOE canister with HFIR inner assembly and (b) profile for HFIR outer assembly. .25

\section{TABLES}

Table 1. Physical properties of the components for a DOE Sealed canister. 3

Table 2. DOE standard canister free volume and surface area for various fuel assembly configurations. 7

Table 3. Fuel assembly decay heats for the simulations of RFA, MURR, and HFIR storage configurations..... .8

Table 4. Maximum fuel element temperatures. ...9

Table 5. Dose rate for MURR fuel in storage. 23

Table 6. Decay heat for MURR fuel in storage. .23

Table 7. Dose rate for HFIR fuel in storage. 24

Table 8. Decay Heat for HFIR fuel in storage. .25 
Page intentionally left blank

viii 


\section{ACRONYMS}

$\begin{array}{ll}\text { ATR } & \text { Advanced Test Reactor } \\ \text { ASNF } & \text { Aluminum-clad Spent Nuclear Fuel } \\ \text { CFD } & \text { Computational Fluid Dynamics } \\ \text { DOE } & \text { Department of Energy } \\ \text { HFBR } & \text { High Flux Beam Reactor } \\ \text { HFIR } & \text { High Flux Isotope Reactor } \\ \text { IFSF } & \text { Irradiated Fuel Storage Facility } \\ \text { INL } & \text { Idaho National Laboratory } \\ \text { MTR } & \text { Materials Test Reactor } \\ \text { MURR } & \text { Missouri University Research Reactor } \\ \text { RFA } & \text { Reference Fuel Assembly } \\ \text { SRNL } & \text { Savannah River National Laboratory } \\ \text { SRS } & \text { Savannah River Site } \\ \text { SNF } & \text { Spent Nuclear Fuel }\end{array}$


Page intentionally left blank 


\section{Modeling of SRS Aluminum-clad Spent Nuclear Fuel in Standard DOE Sealed Canisters}

\section{INTRODUCTION}

The Savannah River Site's L Area Material Storage Facility (known as L Basin) is used by DOE for the storage of domestic and foreign research reactor spent fuel. The fuel consists primarily of highly enriched uranium in metal, oxide of silicide form. By volume, over 30\% of the DOE stored fuel is aluminum clad (though only $10 \%$ by MTHM) (SNFWG, 2017). The Savannah River Site (SRS) has approximately 7 MTHM of aluminum-clad material (SNFWG 2017). In this study, the inventory of the aluminum-clad spent nuclear fuel (ASNF) stored in L-Basin at SRS is studied for its thermal profiles and dose rates over a 50-year period of storage time within a sealed DOE standard canister. One disposition path for the fuel is packaging and shipping in DOE standard canisters which are "road-ready" storage when dried and backfilled with helium. The fuel is removed from wet storage, dried to remove residual water then placed in packing configurations inside DOE standard canisters which are backfilled with helium and sealed.

By the year 2035, there will be $\sim 2500$ MTHM of SNF that will require geologic repository disposal that is managed by DOE. Approximately 400 MHTM of this is currently not packaged. Previous studies in support of geologic disposal divided the DOE SNF inventory into 34 groups based on fuel matrix, cladding, cladding condition and enrichment. The six aluminum clad fuel types are of interest as aluminum is significantly less corrosion resistant than stainless steel and zircaloy clad fuel, and the aluminum cladding contains a hydrated oxide layer that can potentially contain bound, both physiosorbed and chemisorbed, water. While there is a wide range of enrichment and burnup profiles across the DOE spent fuel inventory, the focus herein is on potential bounding cases of the SRS stored ASNF fuel.

The modeling will consist of three different fuel types which should bound the ASNF inventory at SRS. The first is the Missouri University Research Reactor (MURR) fuel. This fuel is the hottest - in terms of decay heat and dosage - that is contained within L Basin. The second is the Reference Fuel Assembly (RFA) - this is a hypothetical assembly that should bound all MTR-type fuel in L Basin. The third fuel is the High Flux Isotope Reactor (HFIR) fuel, this fuel contains the largest surface area per assembly, so it has the potential to also contain the largest mass of oxide for radiolytic generation of hydrogen. The specifications for the storage of the HFIR assembly are to separate the inner and outer annulus to be placed in separate canisters. The modeling here solves for the thermal fields using a computational fluid dynamics (CFD) model of these storage configurations, which should bound all potential scenarios for the ASNF inventory at SRS.

The flow in storage containers of spent nuclear fuel is primary driven through natural convection as air is heated from the central fuel and cooled by the outer air (Nishimura et al. 1996; Lee et al. 2000; Lee 2013; Heng et al. 2002). Several experimental studies have characterized the flow field and temperatures for commercial fuel storage casks (Bang et. al 2015; Jeong et al 2016; Smith 2016; Takeda 2008). Prior modeling of thermal fields and convective patterns with computational fluid dynamics (CFD) have focused on steady state simulations with conditions set for either early or late into the storage cycle (Lee et al. 2000; Li 2016 et al.; Yoo 2010 et al.; Lee 2009 et al.; Povskas 2017 et al.; Brewster 2012 et al.; Kim 2014 et al.; Tseng 2011 et al.; Herranz 2015 et al., Wu et al. 2018). Sensitivities to the parameters of the SNF storage have been studied in these systems for peak cladding temperature to ensure no melting of the plating occurs under the steady state conditions examined (Herranz et al. 2015; Kim 2014 et al.).

Improvements to basic models have used commercial packages to fully resolve the fuel configurations in lieu of coarse-resolution porous media models (Brewster et al. 2012). However, many past CFD models have not coupled the thermal and convective fields with the harmful chemical species which occur due to the radiolytic breakdown of water vapor, nitrogen, oxygen and carbon dioxide that is present within vented canisters (Wittman and Hanson 2015; Arkhipov 2007; Atkinson 2004). In addition, the past CFD 
models have not looked at the transient evolution of the thermal fields inside canisters, opting for steady state solutions. The transient solution allows for the model to track the amount species, such as nitric acid and hydrogen, that can form inside the canister over time.

This study resolves the thermal state of RFA, MURR, and HFIR fuels stored in sealed standard DOE canisters over a 50-year evolution. Dose rates for the fuel cladding surface over the 50-year period are also calculated, for eventual use in coupling with the radiolytic hydrogen yield from the oxide surface layer. This data will be coupled with a Cantera model to solve for the full radiolytic chemistry associated with sealed DOE canisters of SRS ASNF when the G-value for hydrogen from the surface layer is finalized.

\section{THEORY AND MODEL DESCRIPTION}

The CAD models were built according to available reference drawings and reports. The decay heat for RFA and HFIR fuel elements were available through previous calculations. Christ Verst at SRNL contributed calculations for the decay heat of the MURR and HFIR assemblies. Primary sources consisted of:

- Ilas, G., Ade, B., and Betzler, B.R., 2015, "Modeling and Simulations for the High Flux Isotope Reactor Cycle 400," Tech. Rep., Oak Ridge National Laboratory, ORNL/TM2015/36.

- Freels, J.D., Bodey, I.T., Armimilli, R.V., Curtis, F.G., Ekici, K., Jain, P.K., 2011, "Preliminary Multiphysics Analyses of HFIR LEU Fuel Conversion using COMSOL," Tech. Rep. Oak Ridge National Laboratory, ORNL/TM-2011/077.

- Sindelar R.L., Leeper, P.A., Dunsmir, M.D., 2012, Reference Fuel Assemble for Dry Storage Demonstration of L Basin Spent Fuel, Tech. Rep. Savanah River National Laboratory, SRNL-TR-2012-00098.

- Kuan, P., 2001, “Origen2 Radionuclide Inventory Calculations for HFBR Spent Fuel Stored at IFSF,” Tech. Rep. Idaho National Engineering and Environmental Laboratory, EDF-2675.

- Snow, S.D. "Design Considerations for the Standardized DOE SNF Canister Internals," 2008, Tech. Rep., DOE/SNF/DSN-19.

- Clawson, K.L, Rich, J.D., Eckman, R.M., Hukari, N.F., Finn, D., and Reese, B.R., 2018, "Climatography of the Idaho National Laboratory $4{ }^{\text {th }}$ Edition," Tech. rep., NOAA Technical Memorandum OAR ARL-278.

- Drawings: DWG-409406, 409407, 507692.

\subsection{Thermal-Fluid Model}

The commercial multiphysics modeling platform STAR-CCM+ is used for modeling the canister (Siemens, 2019). The numerical solver implemented here is a finite-volume approach with second-order implicit time stepping and a second-order discretization scheme. The segregated flow solver for the Navier-Stokes equations is used, which is applicable to constant density or mildly compressible flows, with a predictor-corrector approach that couples the momentum and continuity equations. A collocated variable arrangement with a Rhie-Chow scheme for pressure-velocity coupling is implemented in a SIMPLE-type algorithm (Siemens, 2019). In the canister scale models, the Reynolds is low enough, so laminar flow is assumed. The momentum equation is then given by 


$$
\frac{\partial(\rho \mathbf{v})}{\partial t}+\nabla \cdot(\rho \mathbf{v} \otimes \mathbf{v})=-\nabla \cdot(p \mathbf{I})+\nabla \cdot \mathbf{T}+\mathbf{f}_{b}
$$

Where $\mathbf{v}$ is the velocity vector, $\mathbf{T}$, is the stress tensor, and $\rho$ is the density. The $\boldsymbol{f}_{b}$ term is the body force, solely occurring due to the buoyancy driven flow in this case. The viscous stress tensor is

$$
\mathbf{T}=\mu\left(\nabla \mathbf{v}+(\nabla \mathbf{v})^{T}\right)-\frac{2}{3} \mu(\nabla \cdot \mathbf{v}) \mathbf{I}
$$

Where $\mu$ is the air viscosity. The mass conservation is expressed through the continuity equation

$$
\frac{\partial \rho}{\partial t}+\nabla \cdot(\rho \mathbf{v})=0
$$

The conservation of energy gives an equation in terms of the total energy, $E$, as

$$
\frac{\partial(\rho E)}{\partial t}+\nabla \cdot(\rho E \mathbf{v})=\mathbf{f}_{b} \cdot \mathbf{v}+\nabla \cdot(\mathbf{v} \cdot \boldsymbol{\sigma})-\nabla \cdot q+S_{E}
$$

Where in the solid phases, the terms with $\mathbf{v}$ are equal to $0, q$ is the conductive heat flux, the energy source term $S_{E}$ is due to the chemical reactions in the fluid phase, and is from the specified heat source for the fuel plates in that solid region. The implicit solver in STAR-CCM+ can typically adapt up to a CourantFriedrichs-Lewy (CFL) condition of nearly 50.

The properties for the materials used for each of the solid regions are shown in Table 1, it is assumed maximum temperatures are low enough to use constant thermal properties for solids.

Table 1. Physical properties of the components for a DOE Sealed canister.

\begin{tabular}{|l|l|l|l|l|}
\hline Material & $\begin{array}{l}\text { Density } \\
{[\mathrm{kg} / \mathrm{m} 3]}\end{array}$ & $\begin{array}{l}\text { Thermal Conductivity } \\
{[\mathrm{W} / \mathrm{m} \mathrm{K}]}\end{array}$ & $\begin{array}{l}\text { Heat Capacity } \\
{[\mathrm{J} / \mathrm{kg} \mathrm{K}]}\end{array}$ & Emissivity [-] \\
\hline $\begin{array}{l}\text { Al-6061 (siding/back plates) } \\
\text { (Polkinhorne, 1991) }\end{array}$ & 2702 & 167 & 896 & 0.82 \\
\hline $\begin{array}{l}\text { Stainless Steel 304 } \\
\text { (Incropera et al. 2007) }\end{array}$ & 7900 & 14.9 & 477 & $\begin{array}{l}0.22 \text { (clean) } \\
0.70 \text { (oxidized) }\end{array}$ \\
\hline $\begin{array}{l}\text { Stainless Steel 316 } \\
\text { (Incropera et al. 2007) }\end{array}$ & 8238 & 13.4 & 468 & $\begin{array}{l}0.22 \text { (clean) } \\
0.70 \text { (oxidized) }\end{array}$ \\
\hline $\begin{array}{l}\text { Carbon Steel } \\
\text { (Incropera et al. 2007) }\end{array}$ & 7854 & 60.5 & 434 & 0.89 \\
\hline $\begin{array}{l}\text { ATR Fuel Plates } \\
\text { (Ilum 1996) }\end{array}$ & 3680 & 42.6 & 614 & 0.82 (assumed) \\
\hline
\end{tabular}




\subsection{Model Geometry}

The descriptions for loaded canister configurations have been specified in DOE/SNF/REP-90, with some modifications for tolerance included in DOE/REP/DSN-19. These geometries have been adapted for canister loading here. While no height for the basket internals is included, the spacing is assumed to be 1 $3 / 4$ " higher than the cropped fuel element heights - the same spacing that is used for the ATR basket design. The first geometry considered is the MURR fuel. This is loaded with 10 fuel elements into a modified Type1 a basket, 3 of these baskets are then placed into a 10-foot-tall 18" diameter DOE standard canister. The CAD model for the packaged canister is shown in Figure 1a, only half-symmetry is modeled for computational efficiency. The Type 1a basket is shown in Figure 1b, and the MURR fuel assembly is shown in Figure 1c. A slice of the domain mesh is shown in Figure 1d, where dark grey is the canister, grey is the basket, light grey is the side plates, red is the fuel plates, and blue shows the free volume air.

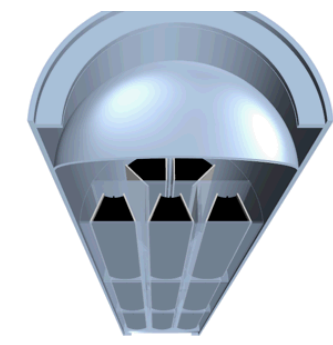

(a)

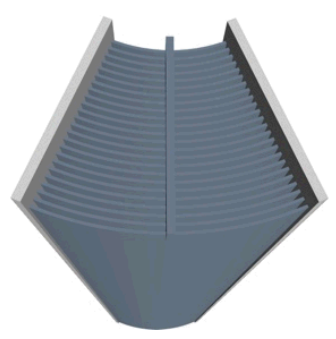

(c)

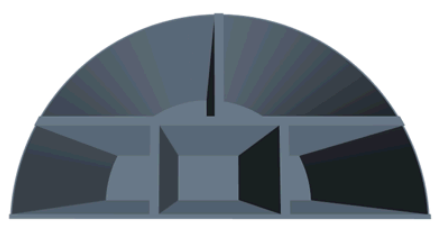

(b)

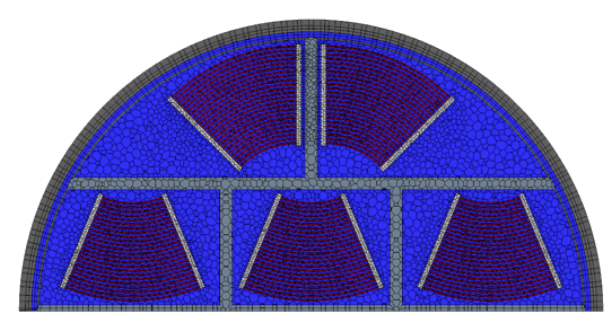

(d)

Figure 1. CAD model for (a) loaded MURR canister, (b) modified Type 1a basket, (c) MURR fuel assembly, and (d) domain mesh slice.

The second case of interest is for the RFA fuel. As this is a hypothetical situation, no exact drawing exists for the RFA fuel, though a typical MTR design is used for reference. This fuel is cropped to 25 inches. Due to the availability of design drawings, the HFBR fuel assembly was used as the reference geometry for the RFA fuel. As with the MURR fuel, this is packed with 10 assemblies in a Type-1a basket then stacked with 3 baskets into a 10-foot-tall 18" DOE standard canister, this is the same basket as Figure 1b. This geometry is shown in Figure 2a. In addition, a hypothetical case for storing a higher packing density is considered. SRNL developed a 14-slot canister design for the RFA to be used within a 10-foot-tall 24" diameter standard canister (Adams et al. 2013). The geometry for this packaged design is shown in Figure 2b, with the basket shown in Figure 2c. The resolved fuel assembly used in both models is shown in in Figure 2d. A slice of the meshed domain is shown in Figure 2e for the Type-1a basket case, and in Figure $2 \mathrm{f}$ for the modified 14-slot basket case. 


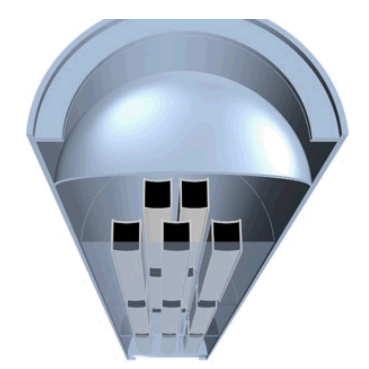

(a)

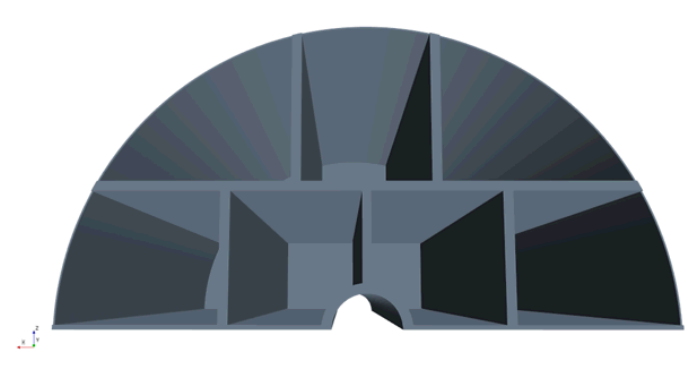

(c)

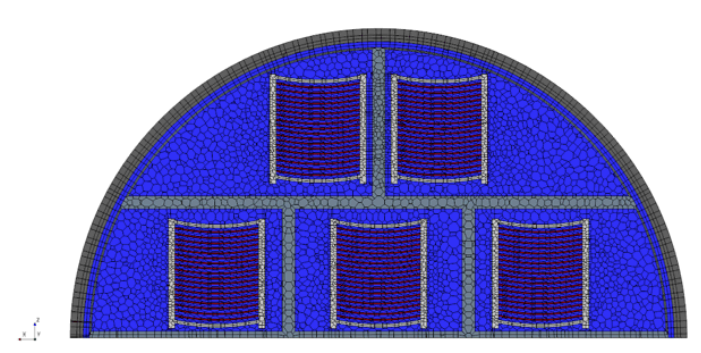

(e)

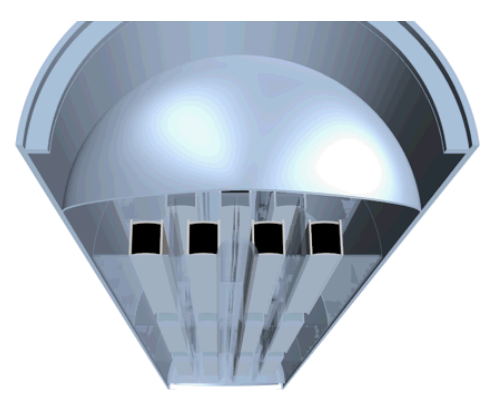

(b)

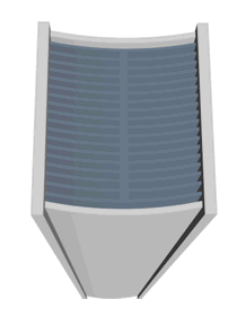

(d)

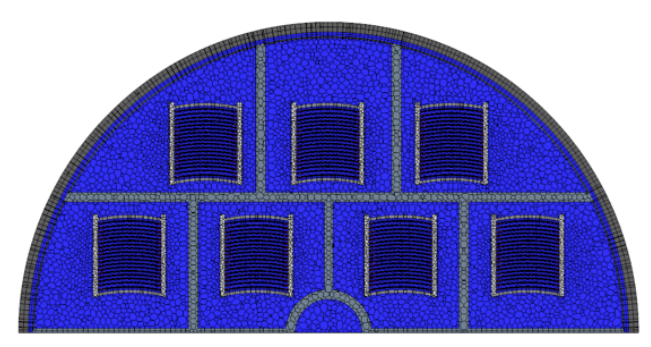

(f)

Figure 2. CAD model for (a) loaded RFA canister, (b) loaded RFA-14 canister, (c) 14-slot basket (d) RFA fuel assembly, (e) Type-1a loading domain mesh slice, and (f) RFA-14 loading domain mesh slice.

The last case of interest is the HFIR fuel assemblies, which contain an inner and outer annulus. For loading these assemblies, the two annuli are separated. Unlike other fuel with layered baskets, the sleeve for the HFIR extends through the entire length of the canister (Snow 2008), and spacers are used between fuel elements. The modified Type $6 \mathrm{a} / 6 \mathrm{~b}$ geometries are utilized for this model. No drawings for spacers exist, though the DOE/DSN-19 report states simply having two $1 / 2$ " thick 12 " diameter plates attached with an 8" pipe attaching them is sufficient for HFIR inner assembly, this is adapted here. For the HFIR outer assembly a 17" diameter spacer plate is used. The HFIR-inner assembly is stacked 3 high in a 10foot-tall 18" diameter DOE standard canister, using 2 spacers between assemblies. The HFIR-outer assembly is stacked 3 high in a 10-foot-tall 24" diameter DOE standard canister, using 2 spacers between assemblies. The CAD model for the packaged HFIR inner assembly storage is shown in Figure 3a, with the basket in Figure 3b, the inner HFIR assembly in Figure 3c and a slice of the domain mesh in Figure $3 \mathrm{~d}$. The CAD model for the packaged HFIR outer assembly storage is shown in Figure 4a, with the basket in Figure 4b, the outer HFIR assembly in Figure $4 c$ and a slice of the domain mesh in Figure 4d. While 
for the previous ATR study, and the above RFA and MURR geometries, a symmetry plane is used, this is not the case for the HFIR, as convergence issues were caused cutting through the middle of the fuel plates, so the full geometry is used.

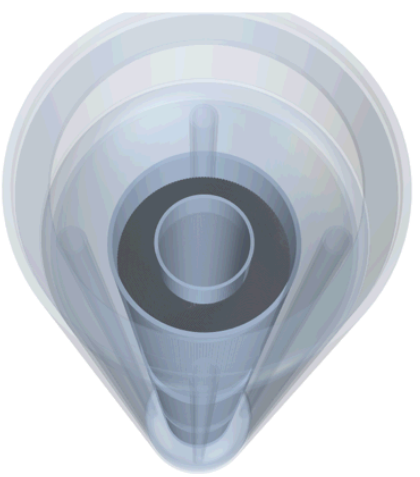

(a)

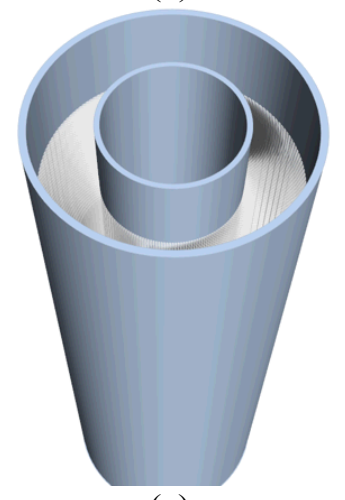

(c)

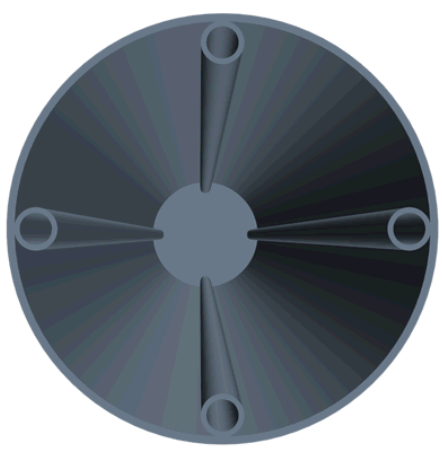

(b)

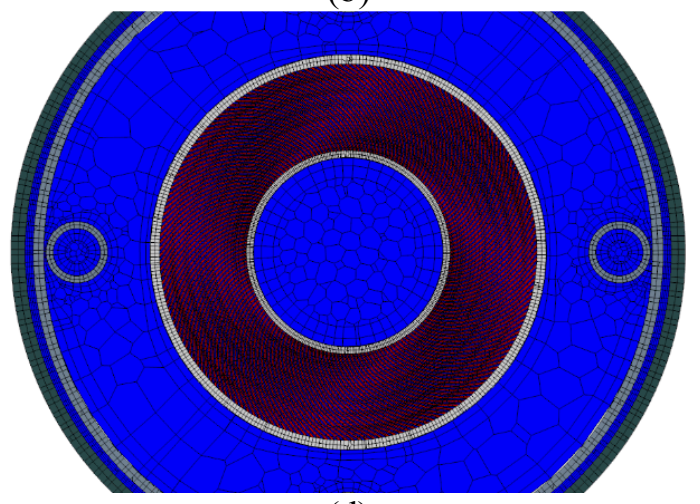

(d)

Figure 3. CAD model for (a) loaded HFIR-inner canister, (b) modified Type 6a basket, (c) HFIR-inner fuel assembly, and (d) domain mesh slice.

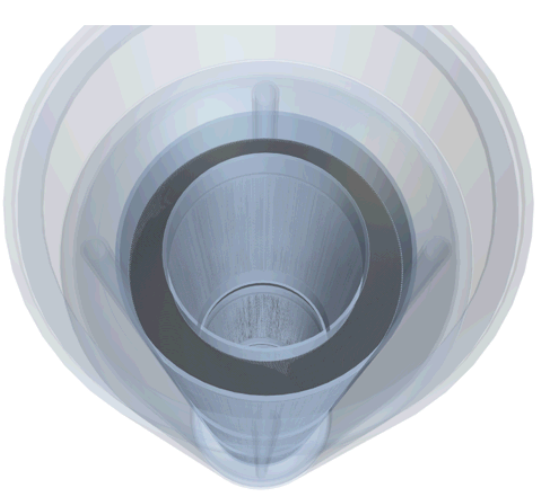

(a)

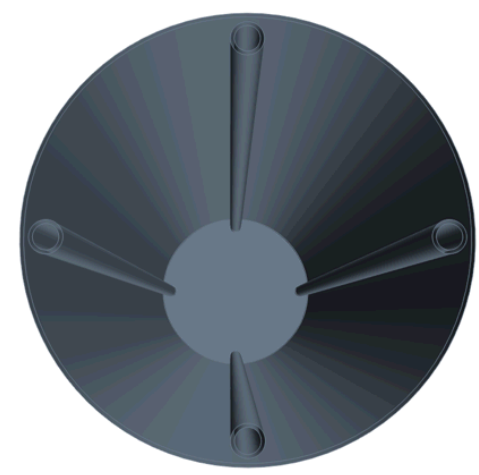

(b) 


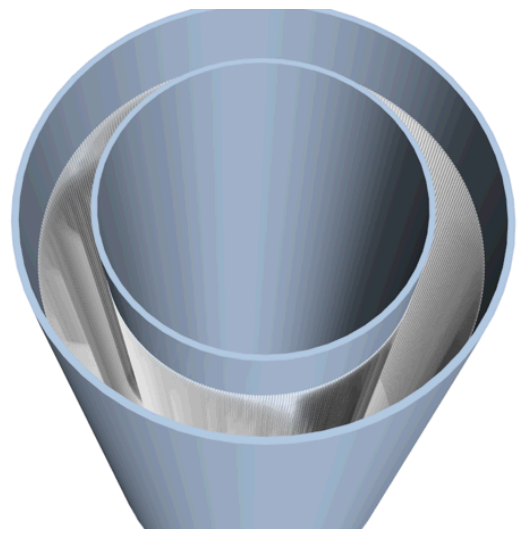

(c)

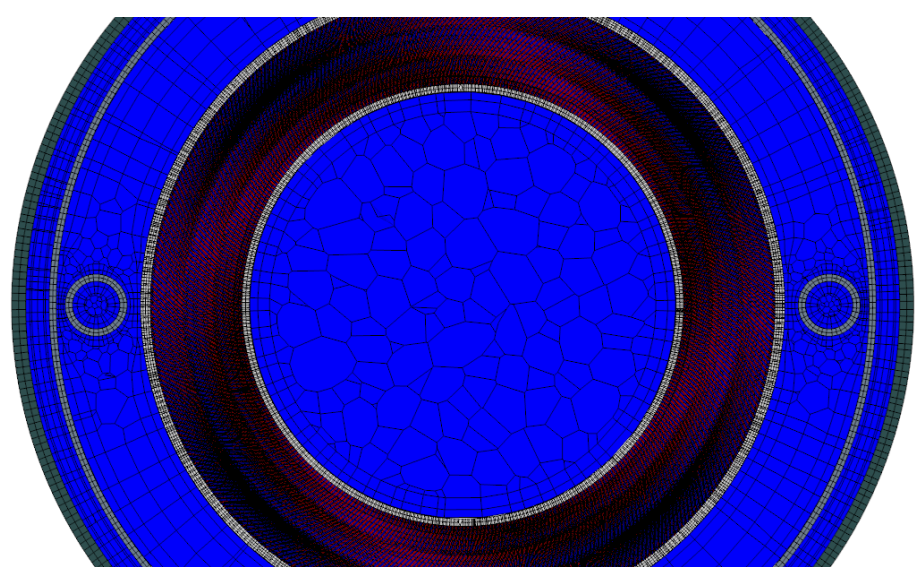

(d)

Figure 4. CAD model for (a) loaded HFIR-outer canister, (b) modified Type $6 \mathrm{~b}$ basket, (c) HFIR-outer fuel assembly, and (d) domain mesh slice.

As part of the preparation for the future chemical modeling, the free volume within each of the canister configurations, as well as the surface area of the aluminum-cladding and side walls is calculated. This free volume takes into account the fuel internals, including the baskets and impact plates present. The previously loaded configuration for the ATF fuel is included for reference. To maintain conservatism, the surface areas include the side plates for ATR/MURR/RFA, and the inner/outer rings of the HFIR. While HFIR outer assembly has the most surface area in terms of the cases considered here, the storage configuration maintains a large amount of free volume due to the large void inside of the HFIR assemblies and between the support pipes of the basket design.

Table 2. DOE standard canister free volume and surface area for various fuel assembly configurations.

\begin{tabular}{|l|l|l|l|}
\hline Configuration & $\begin{array}{l}\text { Total Surface } \\
\text { Area }\end{array}$ & Free Volume & Ratio \\
\hline ATR 15 foot 18” D (reference) & $120 \mathrm{~m}^{2}$ & $450 \mathrm{~L}$ & 0.267 \\
\hline MURR 10 foot 18” D & $78.8 \mathrm{~m}^{2}$ & $284 \mathrm{~L}$ & 0.277 \\
\hline RFA 10 foot 18" D & $50.8 \mathrm{~m}^{2}$ & $297 \mathrm{~L}$ & 0.171 \\
\hline RFA-14 10 foot 24" D & $71.2 \mathrm{~m}^{2}$ & $547 \mathrm{~L}$ & 0.130 \\
\hline HFIR-inner 10 foot 18” D & $56.9 \mathrm{~m}^{2}$ & $296 \mathrm{~L}$ & 0.192 \\
\hline HFIR outer 10 foot 24” D & $108.4 \mathrm{~m}^{2}$ & $548 \mathrm{~L}$ & 0.198 \\
\hline
\end{tabular}

\subsection{Thermal Decay Heat and Ambient Conditions}

As with the prior reports, an assumption is made that yearly temperatures for a 50-year storage scenario would mimic the conditions seen in the IFSF facility (Abboud and Huang, 2019). Ambient temperatures for the INL INTEC CPP-603 facility are described in Christensen (2003a, b). A plot of the ambient temperature conditions measured when the facility had working thermocouples in 2011 is shown in Figure 4, with 9 thermocouples, these are recorded once per hour. These are recorded over a year-long period, for longer term simulations, this data is considered periodic in nature. The thermocouple data is broken down further showing the trend over a single week and showing the whole data set in weeklong 
increments in Figure 4b. The ambient temperature within the facility itself has a very small variation within it compared to the exterior climate due to the large amount of mass of spent fuel stored within it. The largest temperature difference in a 12-hour span is only $1.5^{\circ} \mathrm{C}$, and largest temperature difference in a week-long span is $4.4^{\circ} \mathrm{C}$. The difference from the average for the minimum and maximum temperatures recorded is also shown in Figure 4c.

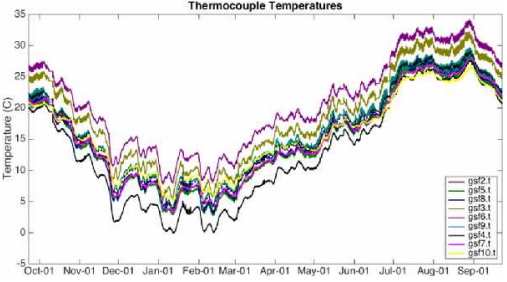

(a)

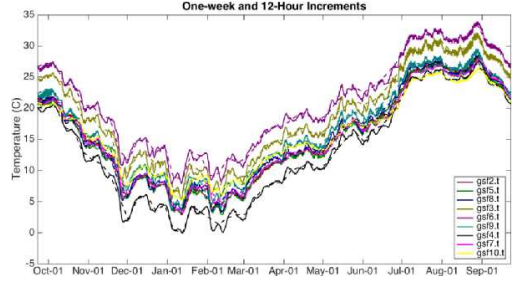

(b)

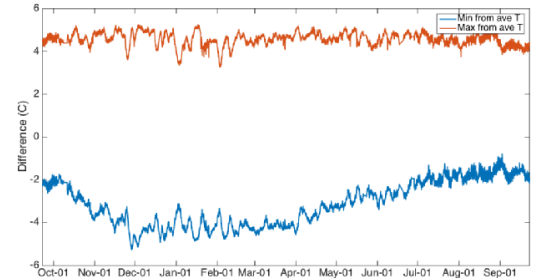

(c)

Figure 5. Thermocouple measurements over 1 year in the INL CPP-603 facility for (a) one-hour intervals, (b) 12-hour and weekly intervals, and (c) maximum and minimum difference from average.

Following previous sensitivity studies, the primary driver for thermal history is the initial decay heat of the fuel. From the limit specified in Sindelar et al. 2012, it was assumed that the RFA and MURR would only be loaded at a maximum of $25 \mathrm{~W}$. This occurs approximately 3 years after reactor discharge for the RFA, it was assumed to use this same period of time for the discharge for the maximum decay heat of the HFIR assembly. Descriptions of the HFIR fuel (Ilas et al. 2015; Freels et al. 2011) list 2.6 and $6.8 \mathrm{~kg} \mathrm{U} \mathrm{U}^{235}$ for the inner and outer assemblies, respectively, these sections are split for storage, so decay heats are calculated for each assembly. Rather than using a Cs-137 decay rate - which is conservative for these fuels during early storage years, the decay heat values were calculated directly. The decay heat for upper, nominal and lower bound cases for the various fuel elements over a 50-year period is shown in Table 3. Decay heat values after reactor discharge for MURR and HFIR fuels were provided by Chris Verst and included in Appendix A.

Table 3. Fuel assembly decay heats for the simulations of RFA, MURR, and HFIR storage configurations.

\begin{tabular}{|l|l|l|l|l|l|l|}
\hline Years after Sealed Storage & \multicolumn{1}{|c|}{0} & \multicolumn{1}{c|}{10} & \multicolumn{1}{c|}{20} & \multicolumn{1}{c|}{30} & \multicolumn{1}{c|}{40} & \multicolumn{1}{c|}{50} \\
\hline RFA High [W] & 25 & 7.82 & 5.92 & 4.73 & 3.89 & 3.05 \\
\hline MURR High [W] & 25 & 4.31 & 3.33 & 2.65 & 3.11 & 1.67 \\
\hline HFIR Outer High [W] & 141.05 & 37.04 & 29.21 & 22.91 & 20.18 & 17.45 \\
\hline HFIR Inner High [W] & 75.95 & 19.94 & 15.72 & 12.33 & 10.86 & 9.39 \\
\hline RFA Nominal [W] & 11.55 & 3.71 & 2.83 & 2.25 & 1.85 & 1.44 \\
\hline MURR Nominal [W] & 13.4 & 4.17 & 3.27 & 2.60 & 2.06 & 1.64 \\
\hline HFIR Outer Nominal [W] & 112.0 & 35.47 & 27.64 & 22.36 & 19.63 & 16.90 \\
\hline HFIR Inner Nominal [W] & 60.31 & 19.10 & 14.88 & 12.04 & 10.57 & 9.1 \\
\hline RFA Low [W] & 5.0 & 3.35 & 2.59 & 2.10 & 1.70 & 1.30 \\
\hline MURR Low [W] & 5.0 & 3.69 & 2.92 & 2.32 & 1.84 & 1.47 \\
\hline HFIR Outer Low [W] & 39.39 & 31.56 & 23.73 & 21.0 & 18.27 & 15.54 \\
\hline HFIR Inner Low [W] & 21.21 & 17.0 & 12.78 & 11.31 & 9.84 & 8.37 \\
\hline
\end{tabular}




\section{RESULTS AND DISCUSSION}

For quick reference, the maximum temperatures for the fuel elements are shown in Table 4. The highest temperature across all cases that were run was $97^{\circ} \mathrm{C}$, for the hypothetical RFA-14 slot basket loaded after 3 years of discharge from reactor. For the more realistic case, the maximum is $86^{\circ} \mathrm{C}$ for MURR assemblies loaded into a canister. The maximum for HFIR outer and inner is $64^{\circ}$ and $55^{\circ} \mathrm{C}$, respectively. These values roughly correlate to packaged fuel 3,5 and 10 years after reactor discharge.

Table 4. Maximum fuel element temperatures.

\begin{tabular}{|l|c|c|c|c|c|}
\hline Max Temperature $\left({ }^{\circ} \mathrm{C}\right)$ & RFA & RFA-14 & MURR & HFIR-outer & HFIR-inner \\
\hline Upper bounds & 89 & 97 & 86 & 64 & 55 \\
\hline Nominal & 61 & 65 & 63 & 58 & 51 \\
\hline Lower bounds & 46 & 48 & 45 & 42 & 39 \\
\hline
\end{tabular}

\subsection{Thermal Profiles}

\subsubsection{RFA}

The temperature profile for the RFA configurations is shown in Figure 6a-i for the 18" canister with the Type-1a loading configuration for slices in the lower middle and upper basket. The hottest region is in the center, and the central basket is a few degrees hotter than the upper and lower baskets. The modified 14-slot basket temperature profiles are shown in Figure 6j-r for the 24" canister configuration. The modified 14-slot basket shows temperatures which are higher than the 10-slot basket from the increased fuel loading. For the hottest case, the average fuel temperature is about $10^{\circ} \mathrm{C}$ below the maximum. The corresponding velocity profiles for these cases are shown with streamlines in Figure 7a-c for the Type 1a basket, and in Figure 7d-f for the modified 14-slot basket, with increasing recirculation at higher decay heats. In the Type-1a basket case, most recirculation is around the outside slots of the basket, and the interior is rather stagnant. The 14-slot basket shows better overall recirculation patterns due to the central hole.

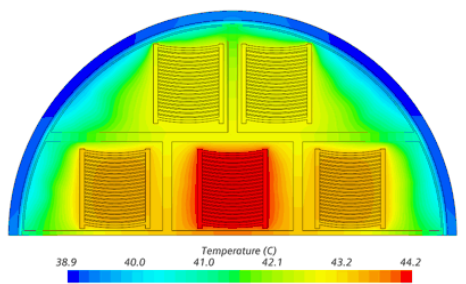

(a)

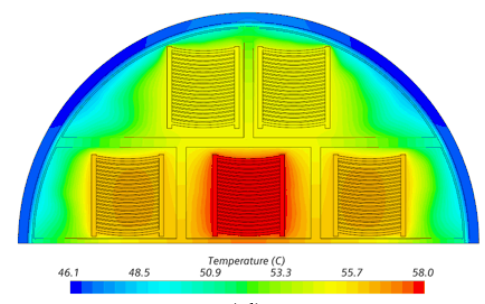

(d)

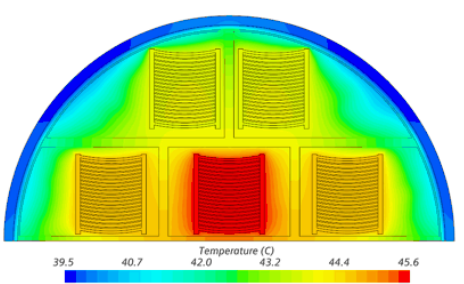

(b)

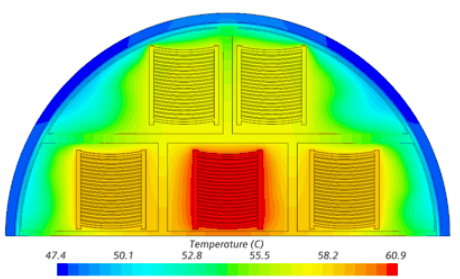

(e)

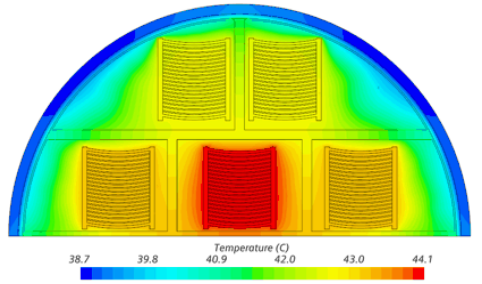

(c)

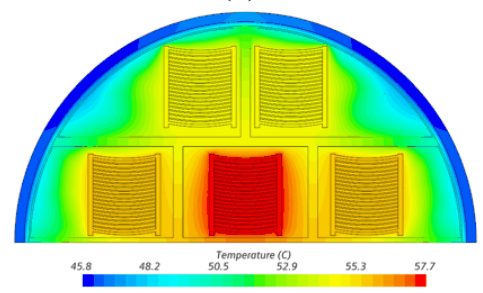

(f) 


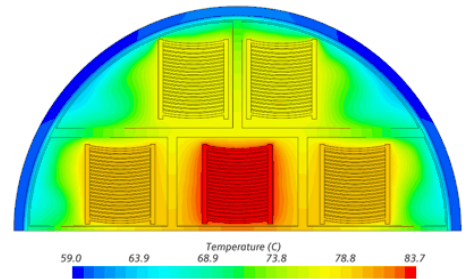

(g)
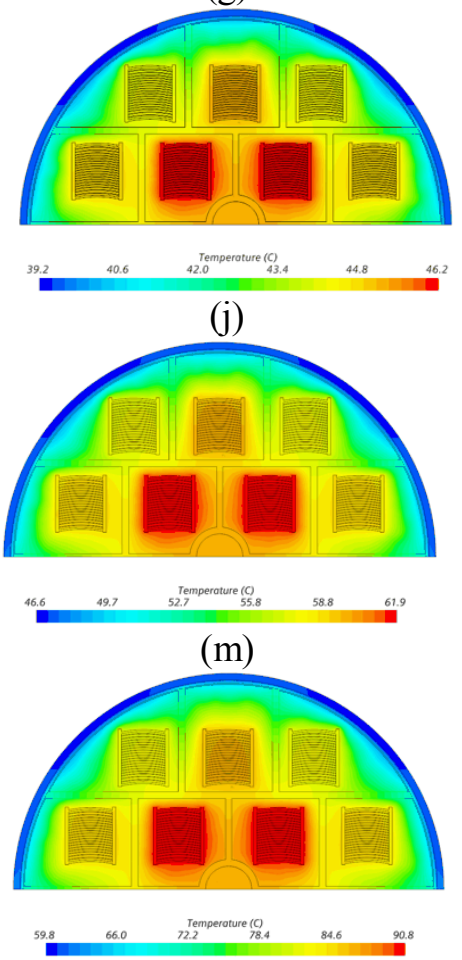

(p)

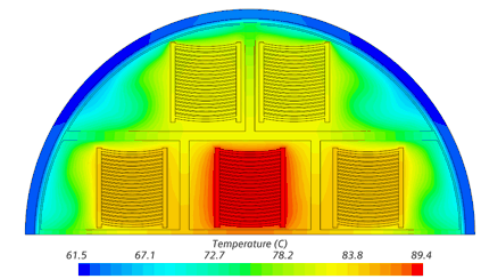

(h)

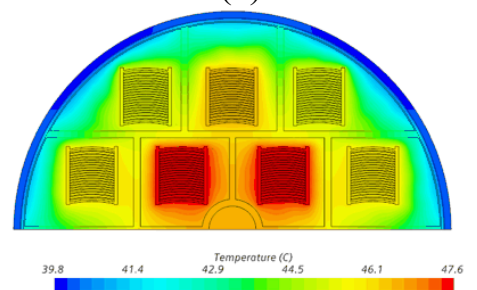

(k)
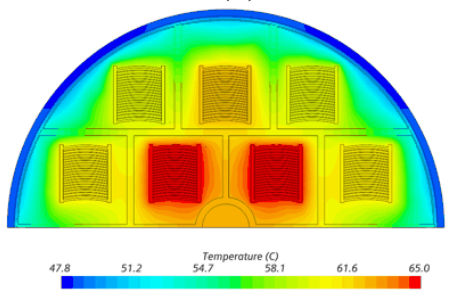

(n)

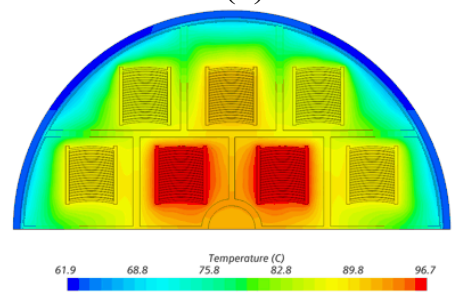

(q)

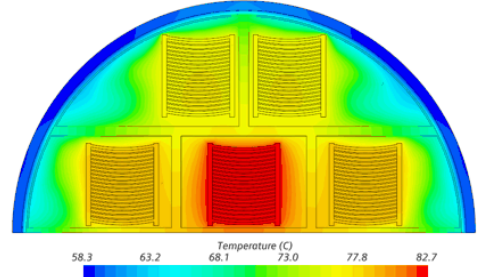

(i)
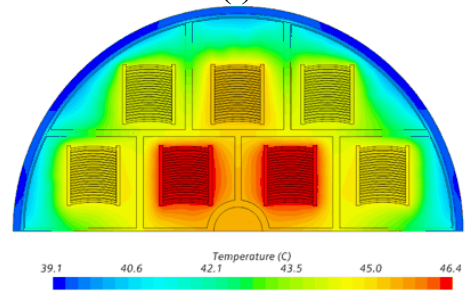

(1)
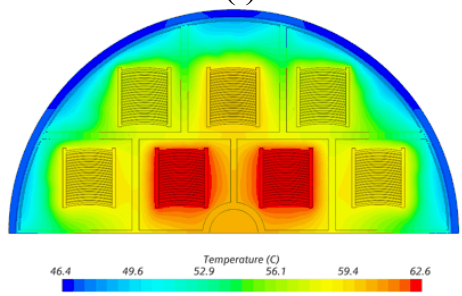

(o)

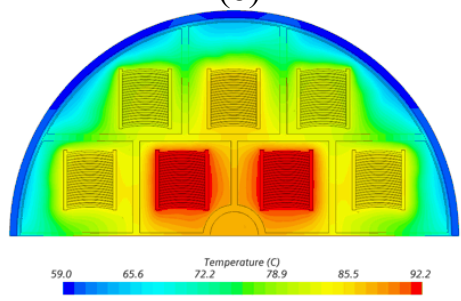

(r)

Figure 6. Temperature contours of RFA for bottom, middle and top bucket for (a-c) Low Q, 18" (d-f) Base Q 18”, (g-i) High Q 18”, (j-1) Low Q 24”, (m-o) Base Q 24”, (p-r) High Q 24”.

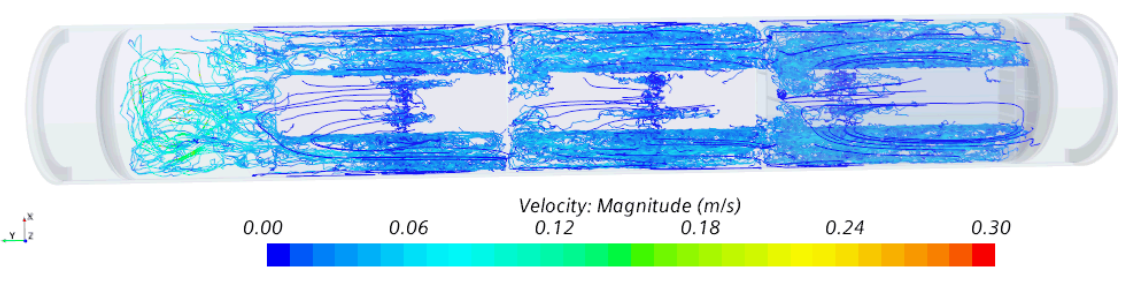

(a)

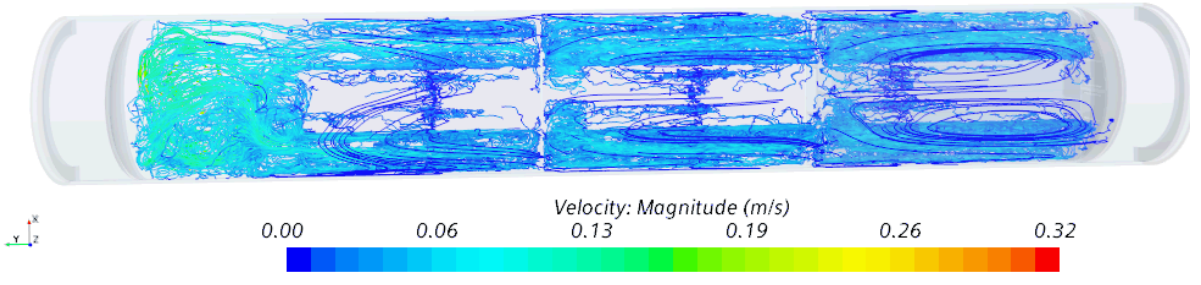

(b) 


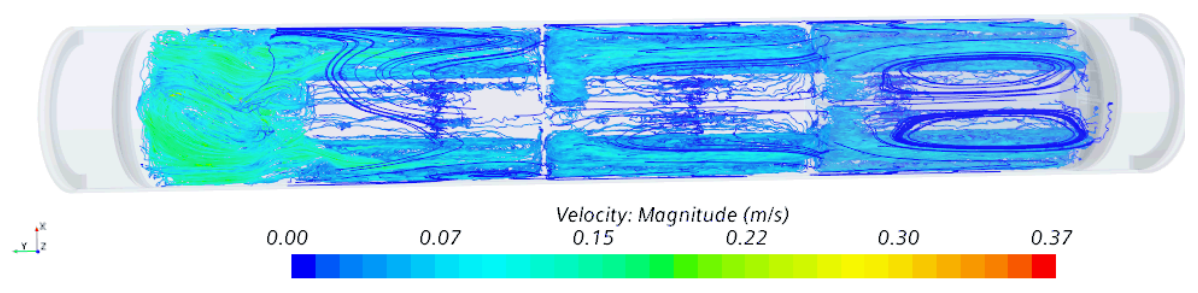

(c)

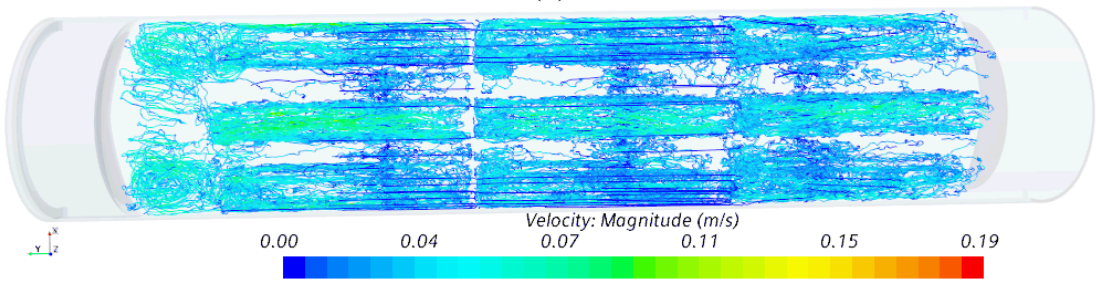

(d)

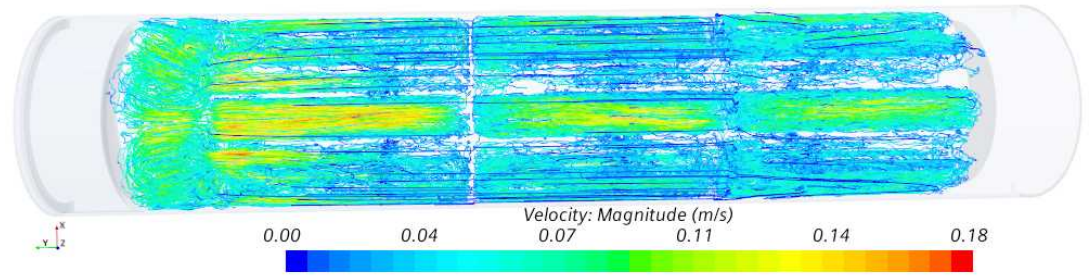

(e)

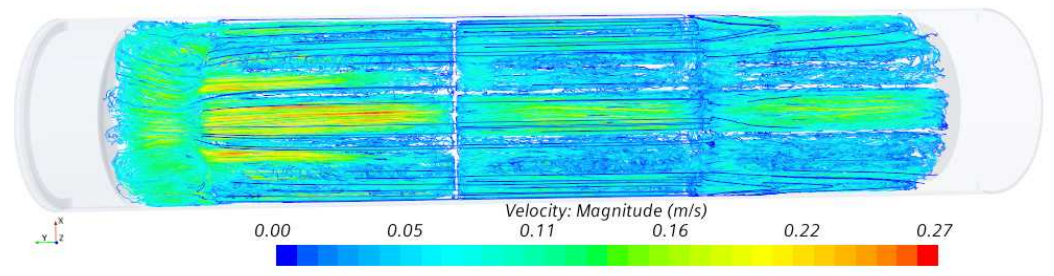

(f)

Figure 7. Velocity streamlines of RFA loaded canister for (a) Low Q 18", (b) base 18", (c) High Q 18", (d) Low Q 24”, (e) Base 24" and (f) High Q 24”.

\subsubsection{MURR}

The temperature profile for the MURR loading configuration is shown in Figure 8a-i for the 18" diameter canister with the Type-1a loading configuration for slices in the lower, middle, and upper basket. The hottest region is in the center, and the central basket is a few degrees hotter than the upper and lower baskets. The MURR loading configuration is very similar in temperatures to the RFA Type-1a basket case, but has slightly lower peak temperatures. The corresponding velocity profiles for these cases are shown with streamlines in Figure 9a-c, with increasing recirculation at higher decay heats.

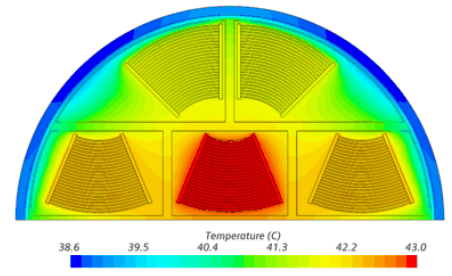

(a)

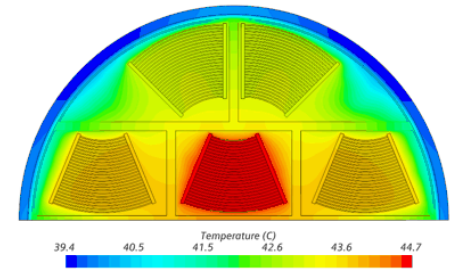

(b)

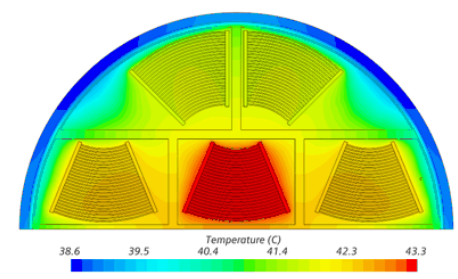

(c) 


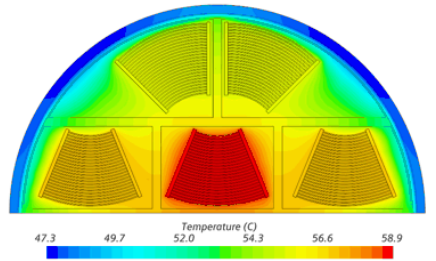

(d)

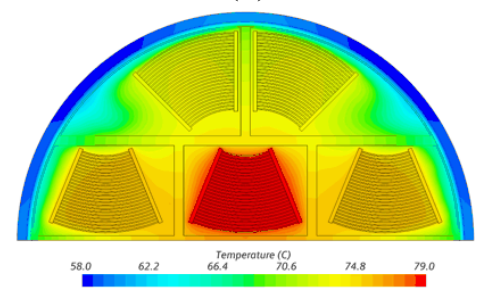

(g)

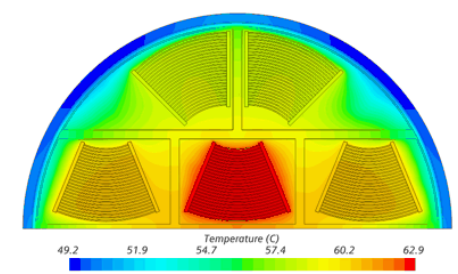

(e)

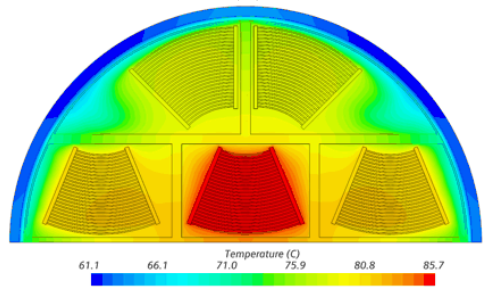

(h)

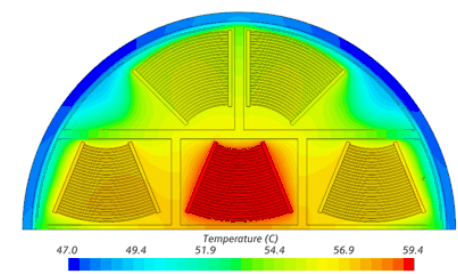

(f)

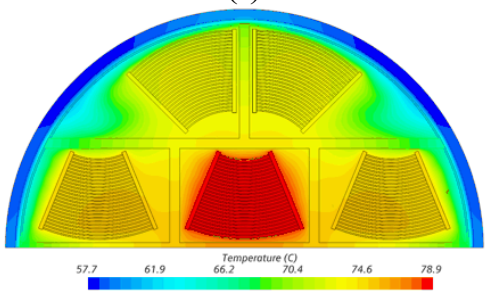

(i)

Figure 8. Temperature contours of MURR loaded canister for bottom, middle and top bucket for (a-c) Low Q, 18" (d-f) Base Q 18", (g-i) High Q 18".

The velocity profiles for the MURR stored fuel are shown in Figure 9. The flow is mostly compartmentalized by the three baskets having their own recirculating region. The largest recirculation occurs in the head above the baskets, as there is about 12 " of free space above the $3^{\text {rd }}$ basket. However, this recirculation is rather weak in the low decay heat case.

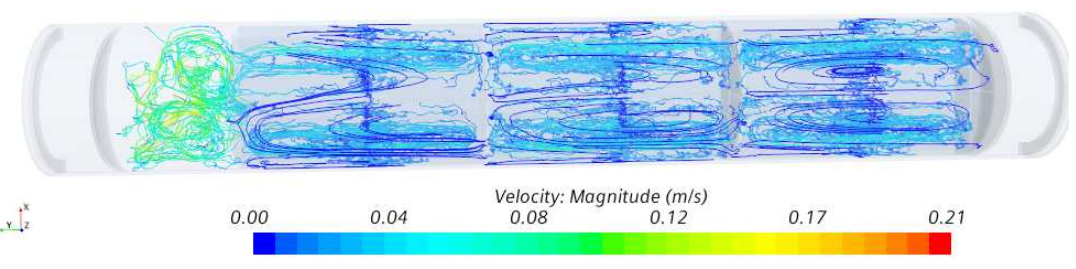

(a)

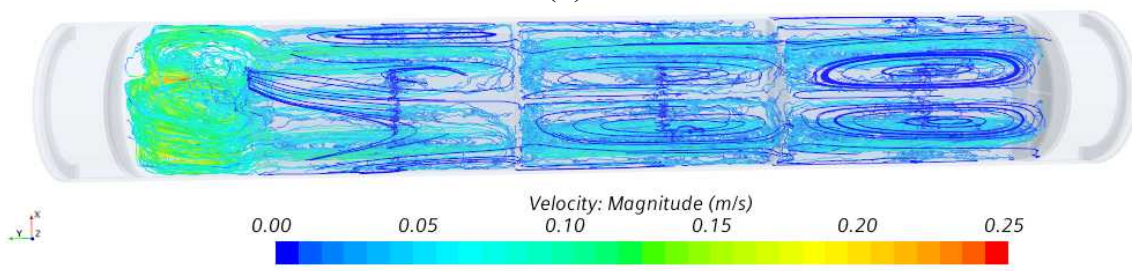

(b)

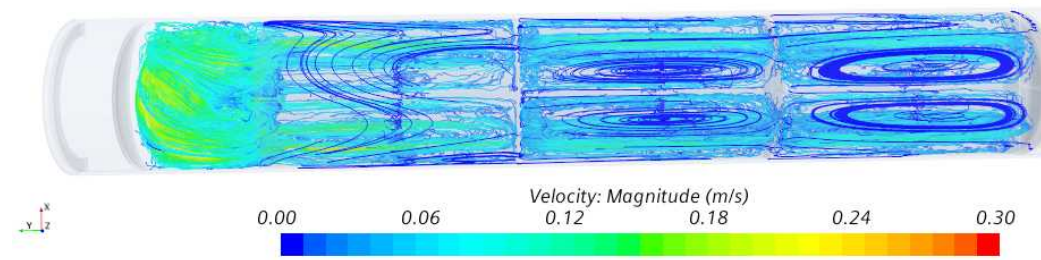

(c)

Figure 9. Velocity streamlines of a MURR loaded canister for (a-c) Low Q, 18" (d-f) Base Q 18”, (g-i) High Q 18". 


\subsubsection{HFIR}

The temperature profiles for the HFIR inner bucket are shown in Figure 10. The total decay heat in this loading configuration is significantly lower than the other fuels, so the temperature is much lower. AS before the hottest region occurs in the center. Unlike the fuel loaded in the Type-1a baskets, the fuel temperatures are nearly uniform horizontally in this case. The uniform heat creates a hot region of gas inside the annulus, though this hot air can escape somewhat in the annulus at the top of the canister. The velocity profiles for the HFIR inner loading are shown in Figure 11. Due to a singular basket design here, the recirculation in both HFIR loaded canisters is much more than in the RFA or MURR packaging configuration.

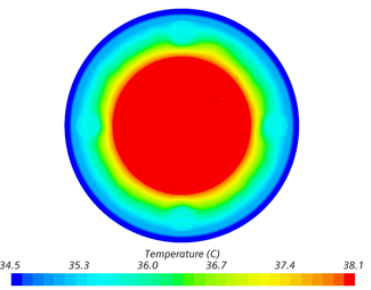

(a)

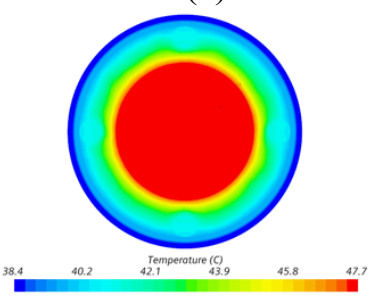

(d)

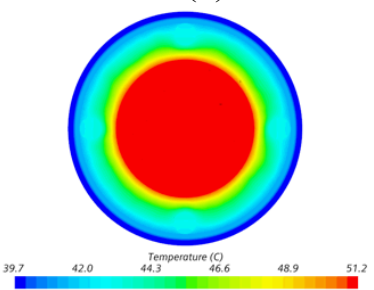

(g)

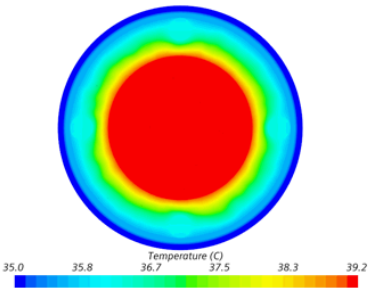

(b)

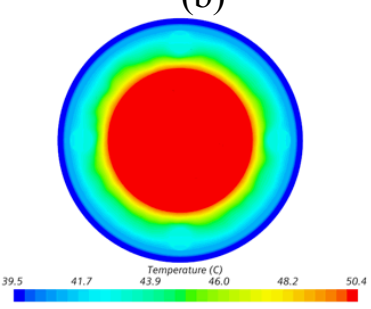

(e)

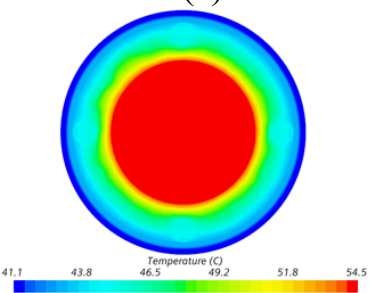

(h)

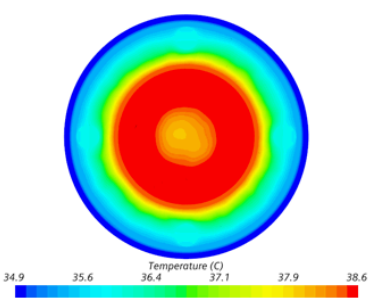

(c)

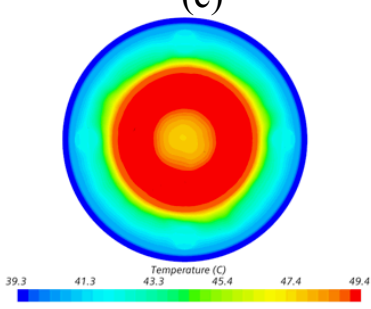

(f)

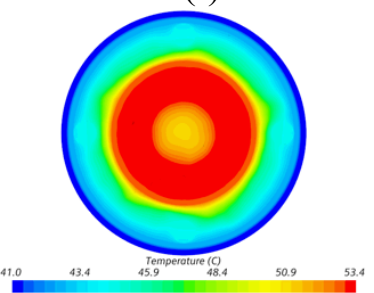

(i)

Figure 10. Temperature contours of HFIR-inner for bottom, middle and top assembly for (a-c) Low Q, 18" (d-f) Base Q 18", (g-i) High Q 18”.

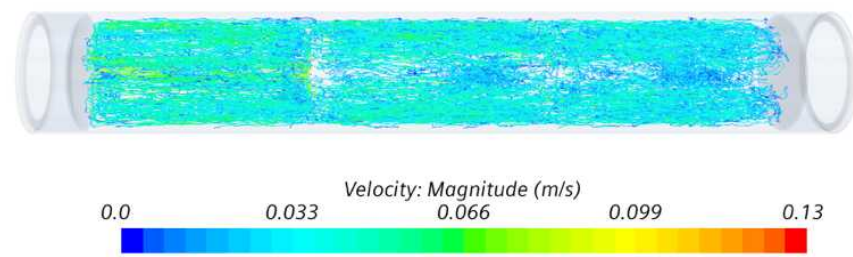

(a) 


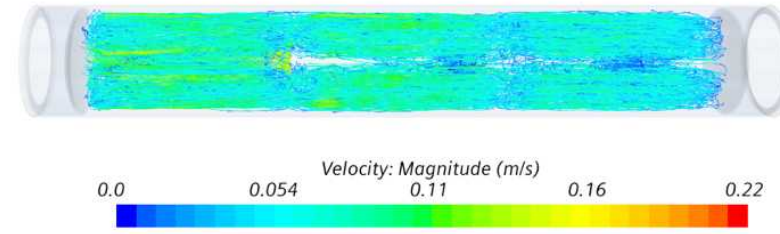

(b)
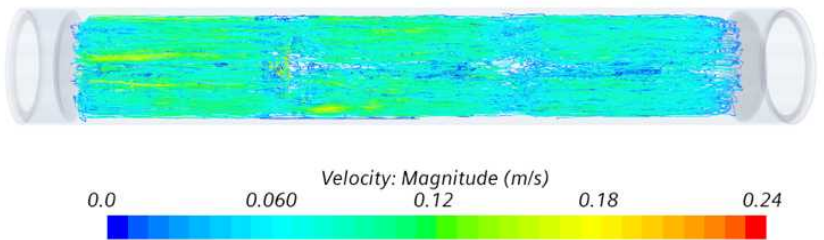

(c)

Figure 11. Velocity streamlines for the HFIR inner loaded canister (a) Low Q, (b) Base Q, and (c) High Q.

The temperature profiles for the HFIR outer assembly are shown in Figure 12. This configuration is slightly hotter than that of the inner annulus but is still much cooler than the RFA or MURR loaded configurations. As with the HFIR inner configuration, the fuel temperature is nearly uniform horizontally, and the gas inside the annulus is kept at a hot temperature, with the exception of the upper fuel assembly The corresponding streamlines of the velocity are shown in Figure 13.

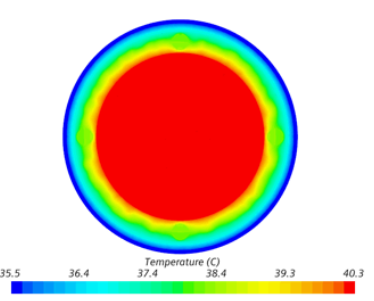

(a)

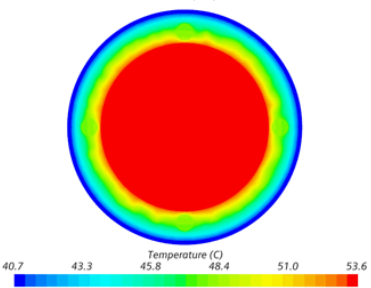

(d)

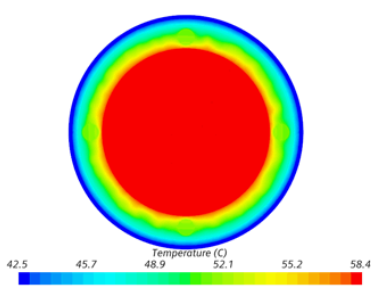

$(\mathrm{g})$

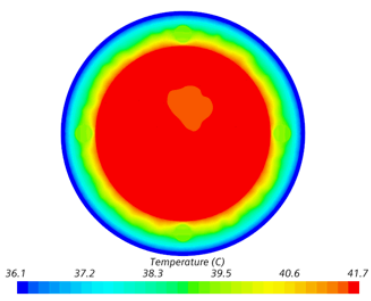

(b)

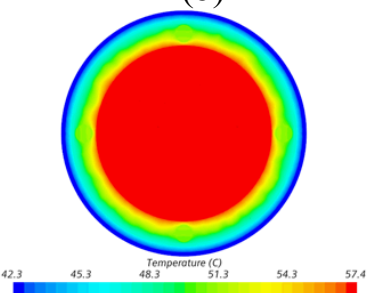

(e)

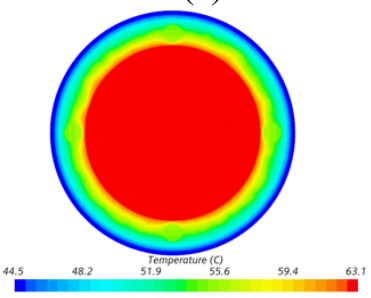

(h)

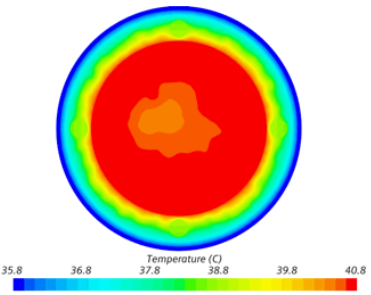

(c)

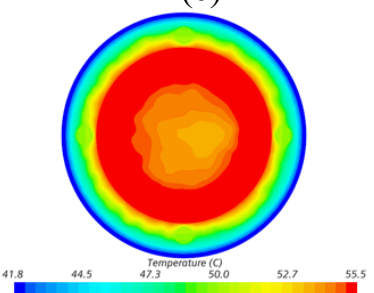

(f)

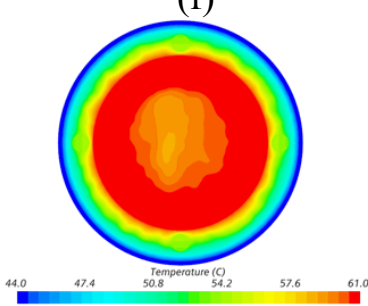

(i)

Figure 12. Temperature contours of HFIR-outer for bottom, middle and top assembly for (a-c) Low Q, 18" (d-f) Base Q 18", (g-i) High Q 18". 


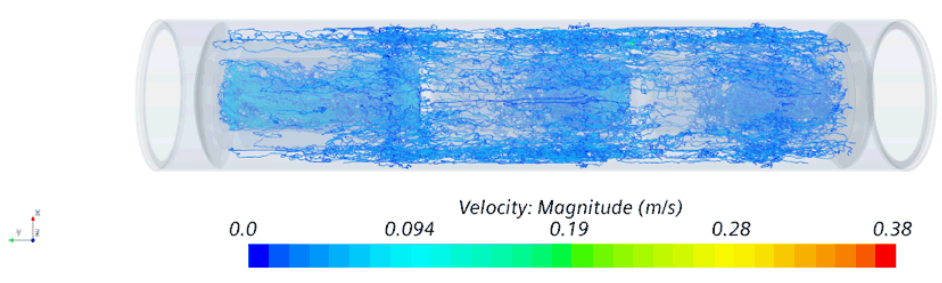

(a)

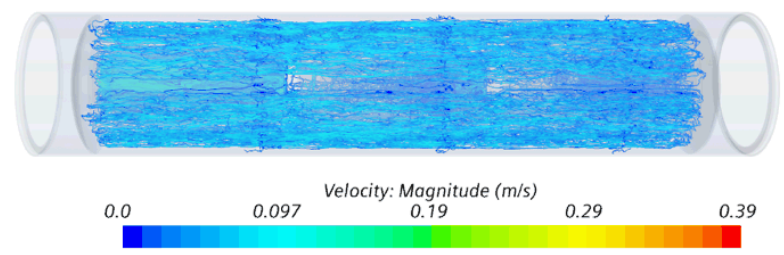

(b)

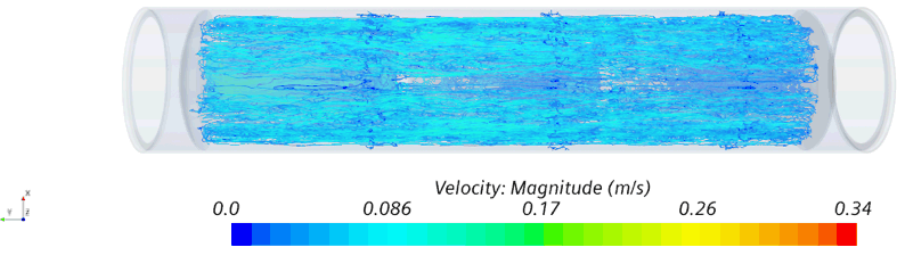

(c)

Figure 13. Streamlines of the velocity in the HFIR-outer loaded canister for (a-c) Low Q, 18" (d-f) Base Q 18”, (g-i) High Q 18”.

\subsubsection{0-year Temperatures}

The average air temperatures for the canisters over a 50-year period for each of the fuels is shown in Figure 14. For the higher decay heat fuel assumptions used, there is a more rapid decay in the temperature profile over the first several years, as many of the shorter half-life radionuclides decay. The temperature fluctuations are from the seasonal temperatures that the canister could see. For lower decay heat fuel, the temperature fluctuations from seasonal effects are greater than the change that occurs from initial packing temperatures to 50-year temperatures. With much less physical mass of fuel present, the canisters loaded with HFIR fuel have more seasonal fluctuations than the rest. Similarly, the RFA-14 loaded canister has less fluctuation seasonally due to the larger amount of physical mass present.

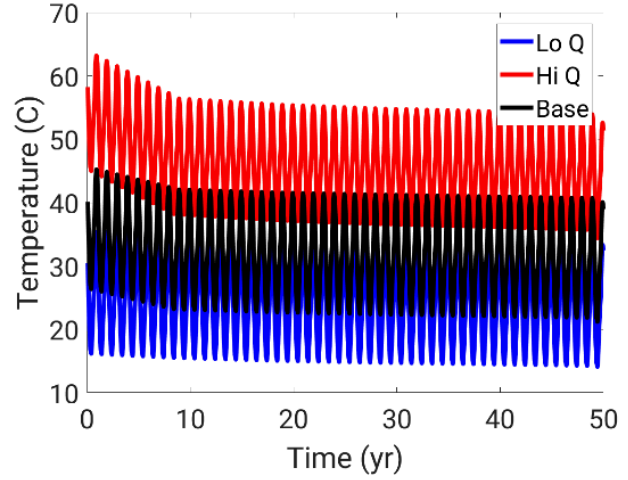

(a)

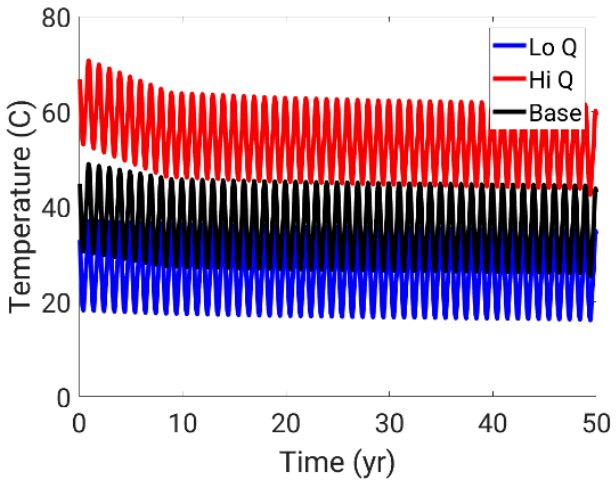

(b) 


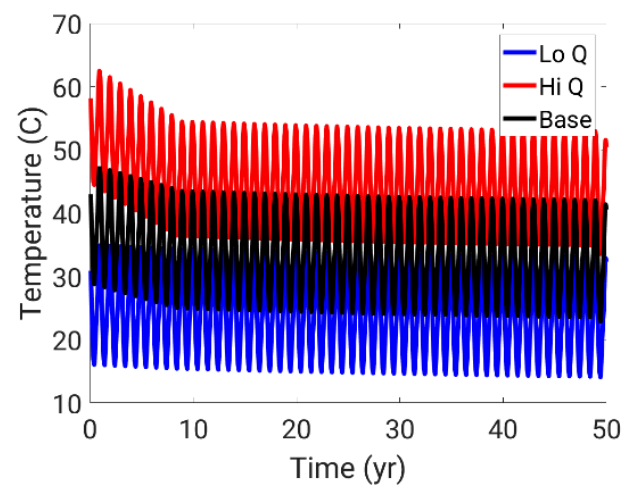

(c)

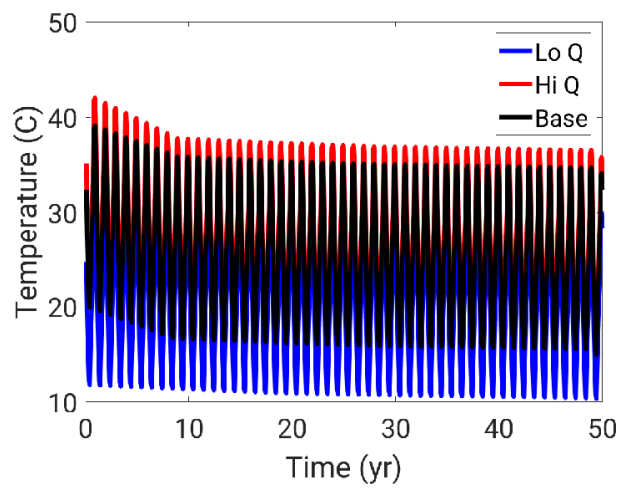

(d)

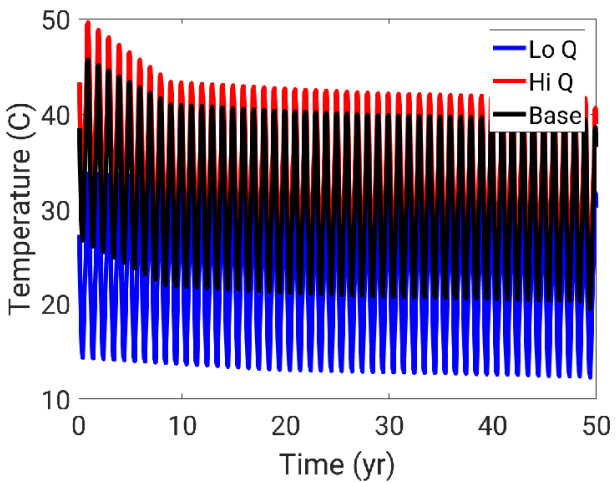

(e)

Figure 14. 50-year average temperatures, for (a) RFA in Type-1a basket, (b) RFA in modified 14-slot basket, (c) MURR in Type 1a basket, (d) HFIR inner in Type 6a basket and (e) HFIR outer in Type 6b basket.

\subsection{Dose Rates}

\subsubsection{RFA}

The RFA is a hypothetical fuel assembly, so no exact radionuclide inventory is specified. Sindelar et al. 2012 lists a material inventory which bounds the radiological hazard. This material inventory activity was bound from selecting the maximum activity of all radioisotopes from a range of fuels. This provides a set of radioisotopes to design basis accident scenarios. However, as this considers the worst case for every isotope, rather than a generalized worst case, the total material content in Curries is $2.31 \times 10^{5}$. This value is an order of magnitude higher than the calculated value of $1.86 \times 10^{4}$ for an ATR assembly rated for a decay heat of $100 \mathrm{~W}$. As such, using this value in a calculation for dose rate would far overestimate radiolytic hydrogen generation by orders of magnitude.

Due to this, the dose rates to be used for the RFA chemical model will be equivalent to the decay of the MURR.

\subsubsection{MURR}

A 2D MCNP model was setup for MURR assemblies within a modified Type-1a canister. This model was set up with one-quarter symmetry for the storage configuration for computational speed. Figure 15 shows the spatial dose rate of the MURR packed in the canister. Table 5 shows the average dose rate to the cladding over 100 year after reactor removal. Due to the differences in burnup, the dose rates to the 
cladding of the MURR are approximately 2 times greater than the dose rates of the ATR stored fuel 0.5278 vs $0.2403 \mathrm{~Gy} / \mathrm{s}$ at 2 years decay.

Based on the maximum ratio of dose rate/decay heat, the dose rate over time in the chemical model for MURR can be estimated [in Gy/s] by

$$
\dot{d}=0.0347 Q
$$

\subsubsection{HFIR}

A 2D MCNP model was setup for HFIR assemblies within a modified Type-6a/b canister for the inner/outer assemblies, respectively. Table 7 shows the average dose rate over time for the cladding for both the inner and outer fuel assembly configurations. The representation of the MCNP homogenized model of the dose rate is shown in Figure 16 for both the HFIR inner and HFIR outer storage configurations. Due to the different burnups of inner/outer assemblies, the dose rates on the cladding are roughly similar between the two. After the initial year of decay, the dose rates for the HFIR are lower than that of the MURR, so using the MURR dose rates for the RFA chemical model will be a more conservative approach.

The dose rate to the cladding for the HFIR assemblies after initial decay can be estimated as a function of the decay heat [in Gy/s] by

$$
\dot{d}=0.00404 Q
$$

For the inner assembly, and

$$
\dot{d}=0.00216 Q
$$

For the outer assembly.

\section{CONCLUSIONS}

The hypothetical RFA fuel packing shows the highest possible maximum temperatures, but only up to $97^{\circ} \mathrm{C}$, which is much lower than previous considerations for packaged ATR fuel. The actual fuel maximum temperatures are 87,64 , and $55^{\circ} \mathrm{C}$ for the MURR, HFIR outer and HFIR inner assemblies. The dose rates for the MURR and HFIR fuels were calculated over a 50-year decay period. Both types of assemblies have slightly higher dose rates than calculated for ATR fuel assemblies. The MURR fuel assemblies have higher dose rates than the HFIR and those values will be used for the RFA geometry.

While, the HFIR assemblies have high fuel element surface areas, the packaging configuration contains a large amount of free volume. Due to the highest surface area to volume ratio for a loaded DOE standard canister, and a high maximum temperature for the aluminum surface, the MURR loaded DOE standard canister should provide a bounding case for all aluminum-clad fuel currently stored at SRS.

As with the simulations that were ran for the ATR fuel stored in a DOE sealed canister, coupled radiolytic chemistry calculations will be done on the storage configurations here. However, the set of simulations will contain updated G-values for the hydrogen generation of the aluminum oxide layer. These updated values will depend upon ongoing experiments for radiolysis tests in helium rather than argon, for dried versus undried samples, and for early versus late time periods. 


\section{REFERENCES}

Abboud A.W. and Huang, H., 2019. Sensitivity Study of Coupled Chemical-CFD Simulations for Sealed and Unsealed Aluminum-clad Spent Nuclear Fuel Storage Canisters. Idaho National Laboratory, Tech. rep. INL/EXT-19-52650.

Adams, T.M., Dunsmuir, M.D., Ledu, D.R., Severynse, T.F., Sindelar, R.L., Moore, E.N., 2013, Dry Storage of Research Reactor Spent Nuclear Fuel, WM2013 Conference, February 24-28, 2013, Phoenix, AZ, USA.

Arkhipov, O.P., Verkhovskaya, A.O., Kabakchi, S.A., and Ermakov, A.N., 2007. Development and verification of a mathematical model of the radiolysis of water vapor. Atomic Energy, 103(5):870.

Atkinson, R., Baulch, D.L., Cox, R.A., Crowley, J.N., Hampson, R.F., Hynes, R.G., Jenkin, M.E., Rossie, M.J., and Troe, J., 2004. Evaluated kinetic and photochemical data for atmospheric chemistry: volume I - gas phase reactions of $\mathrm{X}, \mathrm{HOx}, \mathrm{NO} 2$, and SOx species. Atmospheric Chemistry and Physics, 4(6): 1461-1738.

Bang, K.-S., Yu, S.-H., Lee, S.-H., Lee, J.-C., Seo, K.-S., 2015. Experimental investigation of heat removal performance of a concrete storage cask. Annals of Nuclear Energy 85, 679-686.

Brewster, R. A., Baglietto, E., Volpenhein, E., Bajwa, C. S., 2012. Cfd analyses of the tn-24p pwr spent fuel storage cask. In proceedings: ASME 2012 Pressure Vessels and Piping Conference. American Society of Mechanical Engineers, pp. 17-25.

Bulearca, A.M., Calinescu, I., and Lavric, V., 2010. Model Studies of NOx and SOx reactions in Flue gas treatment by electron beam. UPB Sci Bull, Series B, 72(1):101-112.

Christensen, A., 2002. EDF-3361, Operating Characteristics of IFSF Confinement Ventilation System. Tech. rep. Idaho National Laboratory.

Christensen, A., 2003a. EDF-2760, The Irradiated Fuel Storage Facility Maximum Heat Load And Resulting Maximum Temperatures When the Ventilation System Is Not Operating. Tech. rep., Idaho National Laboratory.

Christensen, A., 2003b. EDF-5579 Corrosion Potential of the Irradiated Fuel Storage Facility Environment. Tech. rep., Idaho National Laboratory.

Clawson, K.L, Rich, J.D., Eckman, R.M., Hukari, N.F., Finn, D., and Reese, B.R., 2018. Climatography of the Idaho National Laboratory $4^{\text {th }}$ Edition. Tech. rep., NOAA Technical Memorandum OAR ARL278.

Freels, J.D., Bodey, I.T., Armimilli, R.V., Curtis, F.G., Ekici, K., Jain, P.K. "Preliminary Multiphysics Analyses of HFIR LEU Fuel Conversion using COMSOL,” Tech. Rep. Oak Ridge National Laboratory, ORNL/TM-2011/077, 2011.

Goodwin, D.G., Moffat, H.K., and Speth, R.L. Cantera: An object-oriented software toolkit for chemical kinetics, thermodynamics, and transport processes. http://www.cantera.org, 2017. Version 2.3.0. doi:10.5281/zenodo. 170284

Glazoff, M.V., Lister, T.E. 2018. Modeling Activities Concerning Aluminum Spent Nuclear Fuel Cladding Integrity. Tech. rep. Idaho National Laboratory, INL/EXT-18-51694.

Hilton, B.A. 2000 Review of Oxidation Rates of DOE Spent Nuclear Fuel Part 1: Metallic Fuel. Tech. rep. Argonne National Laboratory, AN-00/24. 
Heng, X., Zuying, G., Zhiwei, Z., 2002. A numerical investigation of natural convection heat transfer in horizontal spent-fuel storage cask. Nuclear Engineering and Design 213 (1), 59-65.

Herranz, L. E., Penalva, J., Feria, F., 2015. Cfd analysis of a cask for spent fuel dry storage: Model fundamentals and sensitivity studies. Annals of Nuclear Energy 76, 54-62.

Ilas, G., Ade, B., and Betzler, B.R. "Modeling and Simulations for the High Flux Isotope Reactor Cycle 400,” Tech. Rep., Oak Ridge National Laboratory, ORNL/TM-2015/36, 2015.

Illum, D.B., 1996. ATR Fuel Summary Report. Tech. Report INEL-96/300.

Incropera F.P., DeWitt ,D.P. , Bergman, T.L. and Lavine, A.S., 2007. Fundamentals of Heat and Mass Transfer, Sixth Edition, John Wiley and Sons, Hoboken, NJ.

Jeong, Y. S., Bang, I. C., 2016. Hybrid heat pipe based passive cooling device for spent nuclear fuel dry storage cask. Applied Thermal Engineering 96, 277-285.

Kim, H., Kwon, O. J., Kang, G.-U., Lee, D.-G., 2014. Comparisons of prediction methods for peak cladding temperature and effective thermal conductivity in spent fuel assemblies of transportation/storage casks. Annals of Nuclear Energy 71, 427-435.

Kim, S. S., Pope, C., Taylor, L. L., et al., 2007. Criticality analysis for proposed maximum fuel loading in a standardized snf canister with type 1a baskets, INL/EXT-07-12326. Tech. rep., Idaho National Laboratory.

Kim, Y.S., Hofman, G.L., Robinson, A.B., Snelgrove, J.L., Hanan, N., 2008. Oxidation of aluminum alloy cladding for research and test reactor fuel. Journal of Nuclear Materials 378, 220-228.

Kuan, P., 2001, "Origen2 Radionuclide Inventory Calculations for HFBR Spent Fuel Stored at IFSF," Tech. Rep. Idaho National Engineering and Environmental Laboratory, EDF-2675.

Lee, D.-G., Park, J.-H., Lee, Y.-H., Baeg, C.-Y., Kim, H.-J., 2013. Natural convection heat transfer characteristics in a canister with horizontal installation of dual purpose cask for spent nuclear fuel. Nuclear Engineering and Technology 45 (7), 969-978.

Lee, J., Choi, W., Bang, K., Seo, K., Yoo, S., 2009. Thermal-fluid flow analysis and demonstration test of a spent fuel storage system. Nuclear Engineering and Design 239 (3), 551-558.

Lee, S. Y., Sindelar, R. L., Losey, D. C., 2000. Thermal modeling and performance analysis of interim dry storage and geologic disposal facilities for spent nuclear fuel. Nuclear technology 131 (1), 124151.

Li, J., Liu, Y. Y., 2016. Thermal modeling of a vertical dry storage cask for used nuclear fuel. Nuclear Engineering and Design 301, 74-88.

Lockheed Martin Idaho Technologies Co, Idaho National Engineering and Environmental Lab, Idaho Falls, ID (United States) (Aug 1998). Preliminary design specification for Department of Energy standardized spent nuclear fuel canisters Volume 1: Design specification (DOE/SNF/REP--011-Vol 1). United States.

Nishimura, M., Shibazaki, H., Fujii, S., Maekawa, I., 1996. Natural convection heat transfer in the horizontal dry storage system for the lwr spent fuel assemblies. Journal of nuclear science and technology 33 (11), 821-828.

Olson, L., Verst, C., d'Entremont, A., Fuentes, R., Sindelar, R., 2019. Characterization of Oxide Fielms on Aluminum Mterials following Reactor Exposure and Wet Storage in the SRS L-Basin. Tech. Rep. Savannah River National Laboratory, SRNL-STI-2019-00058. 
Parker-Quaife E.H., Horne, G.P., Heathman, C.R., Verst, C., Zalupski, P.R. 2019. Radiation-Induced Molecular Hydrogen Gas Generation by Pre-Corroded Aluminum Alloy 1100. Tech Rep. Idaho National Laboratory, INL/EXT-19-55202.

Polkinghorne, S.T. and Lacy, J.M., 1991. Thermophysical and Mechanical Properties of ATR Core Materials, Report No. PG-T-91-031, EG\&G Idaho Inc.

Po`skas, R., S`imonis, V., Po`skas, P., Sirvydas, A., 2017. Thermal analysis of castor rbmk-1500 casks during long-term storage of spent nuclear fuel. Annals of Nuclear Energy 99, 40-46.

Shih, T.-H., Liou, W.W., Shabbir, A., Yang, Z. and Zhu, J. 1994. "A New k-e Eddy Viscosity Model for High Reynolds Number Turbulent Flows -- Model Development and Validation”, NASA TM 106721.

Siemens, 2019. User Guide: Star-ccm+ v14.06.011R8.

Sindelar, R.L., Leeper, P.A., Dunsmil, M.D., 2012, "Reference Fuel Assembly for Dry Storage Demonstration of L-Basin Spent Fuel”, Tech. Rep. Savannah River National Laboratory, SRNL-TR2012-00098.

Smith, B. L., 2016. Validation experiments for spent-fuel dry-cask in-basket convection. Tech. rep., Utah State Univ., Logan, UT (United States).

SNFWG, 2017, Aluminum Clad Spent Nuclear Fuel: Technical Considerations and Challengeds for Extended ( $>50$ years) Dry Storage. Tech. Rep. Department of Energy, DOE/ID RPT 1575.

Snow, S.D, 2008. "Design Considerations for the Standardized DOE SNF Canister Internals," Tech. Rep., $\mathrm{DOE} / \mathrm{SNF} / \mathrm{DSN}-19$.

Solis, J., Zigh, G., 2016. Impact of variation in environmental conditions on the thermal performance of dry storage casks, nureg-2174. Tech. rep., U.S. NRC.

Solıs, J., Zigh, G., 2017. Best practice guidelines for the use of cfd in dry cask applications.

Stewart, D., 2012, ECAR-2906. ATR Fuel Element In-Air Dose Rate Estimates Base on Heat Generation, Tech rep., Idaho National Laboratory.

Takeda, H., Wataru, M., Shirai, K., Saegusa, T., 2008. Development of the detecting method of helium gas leak from canister. Nuclear Engineering and Design 238 (5), 1220-1226.

Tseng, Y., Lin, C., Shih, C., Wang, J., 2016. Evaluating the feasibility of new surveillance concept for dry storage system through cfd methodology. Nuclear Engineering and Design 304, 1-10.

Tseng, Y.-S., Wang, J.-R., Tsai, F. P., Cheng, Y.-H., Shih, C., 2011. Thermal design investigation of a new tube-type dry-storage system through cfd simulations. Annals of Nuclear Energy 38 (5), 1088 1097.

Vedder, W. and Vermilyea, D.A. 1968. Aluminum + Water Reaction. Trans. Faraday Soc, 65, pp.5 61584.

Wertsching, A.K., Hill, T.J., Mackay, N. and Birk, S.M., 2007. Material Interactions on Canister Integrity During Storage and Transport. Tech. rep. Idaho National Laboratory, DOE/SNF/REP-104.

Westbrook, M.L., Sindelar, R.L., Fisher, D.L. 2015. Radiolytic hydrogen generation from aluminum oxyhydroxide solids: theory and experiment. J. Radioanal. Nucl. Chem., 303, pp 81-86.

Wittman, R., Hanson, B., 2015. Radiolysis model analysis for a used fuel storage canister. In proceedings: IHLRWM April 2015.

Wu, Y., Klein, J., Zhou, H., Zuo, L., 2018. Thermal and fluid analysis of dry cask storage containers over multiple years of service. Annals of Nuclear Energy 112, 132-142. 
Yoo, S. H., No, H. C., Kim, H. M., Lee, E. H., 2010. Full-scope simulation of a dry storage cask using computational fluid dynamics. Nuclear Engineering and Design 240 (12), 4111-4122.

Zigh, G., Solis, J., 2013. Computational fluid dynamics best practice guidelines for dry cask applications, nureg-2152. Tech. rep., U.S. NRC.

\section{DRAWING LIST}

INL DWG-507692 DOE Sealed Standard Canister

INL DWG-409406 MURR Fuel Plate

INL DWG-409407 MURR Fuel Assembly 
Page intentionally left blank 


\section{Appendix A \\ MURR and HFIR Decay Heat and Dose Rate Calculations}

Chirst Verst of SRNL provided the following decay heat and dose rate calculations for the MURR fuel assemblies and the HFIR fuel assemblies.

Table 5. Dose rate for MURR fuel in storage.

\begin{tabular}{|l|c|c|}
\hline $\begin{array}{l}\text { Years after } \\
\text { reactor discharge }\end{array}$ & $\begin{array}{c}\text { Dose Rate } \\
{[\mathrm{krad} / \mathrm{hr}]}\end{array}$ & $\begin{array}{c}\text { Dose Rate } \\
{[\mathrm{Gy} / \mathrm{s}]}\end{array}$ \\
\hline 1 & 538 & 1.494 \\
\hline 2 & 190 & 0.5278 \\
\hline 5 & 85 & 0.2361 \\
\hline 10 & 60 & 0.1667 \\
\hline 25 & 40 & 0.1111 \\
\hline 50 & 21 & 0.05833 \\
\hline 100 & 7 & 0.01944 \\
\hline
\end{tabular}

Table 6. Decay heat for MURR fuel in storage.

\begin{tabular}{|r|r|}
\hline Decay [d] & \multicolumn{1}{l|}{ Total } \\
\hline 60 & 341.093 \\
\hline 120 & 198.0652 \\
\hline 180 & 131.0835 \\
\hline 240 & 93.06896 \\
\hline 300 & 70.50916 \\
\hline 365 & 55.34472 \\
\hline 420 & 46.72079 \\
\hline 480 & 39.84821 \\
\hline 540 & 34.62737 \\
\hline 600 & 30.46896 \\
\hline 660 & 27.05758 \\
\hline 730 & 23.75411 \\
\hline 780 & 21.73718 \\
\hline 840 & 19.63724 \\
\hline 900 & 17.81952 \\
\hline 960 & 16.2508 \\
\hline 1020 & 14.88129 \\
\hline 1095 & 13.41219 \\
\hline 1140 & 12.64859 \\
\hline 1688 & 7.481056 \\
\hline 2191 & 5.882525 \\
\hline 2739 & 5.160475 \\
\hline & \\
\hline 6 \\
\hline
\end{tabular}




\begin{tabular}{|r|r|}
\hline 3287 & 4.78368 \\
\hline 3835 & 4.527218 \\
\hline 4383 & 4.321378 \\
\hline 4931 & 4.142912 \\
\hline 5479 & 3.981029 \\
\hline 6027 & 3.830757 \\
\hline 6575 & 3.689607 \\
\hline 7123 & 3.555089 \\
\hline 7671 & 3.427195 \\
\hline 8219 & 3.30511 \\
\hline 8767 & 3.187997 \\
\hline 9315 & 3.075026 \\
\hline 9863 & 2.966196 \\
\hline 10411 & 2.862338 \\
\hline 10959 & 2.7618 \\
\hline 11507 & 2.664582 \\
\hline
\end{tabular}

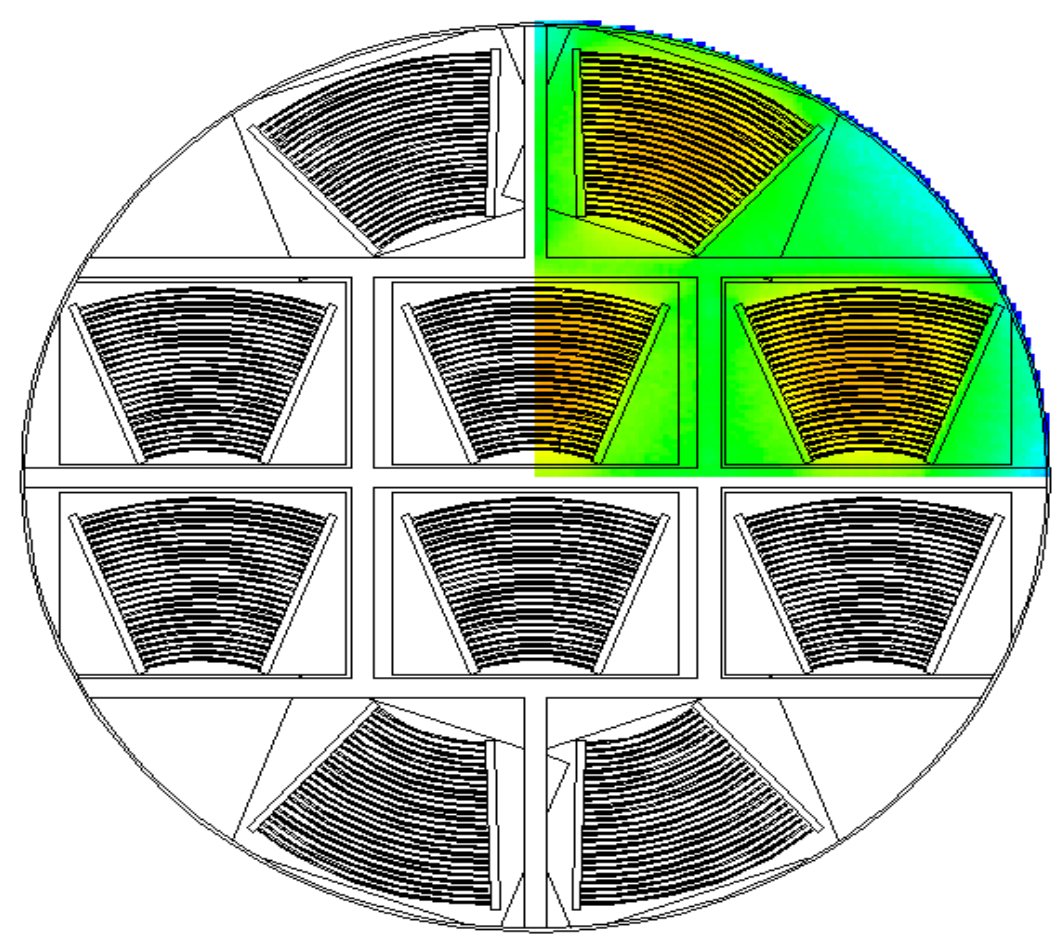

Figure 15. Dose rate contour profile for standard DOE canister with MURR fuel loaded.

Table 7. Dose rate for HFIR fuel in storage.

\begin{tabular}{|l|c|c|c|c|}
\hline $\begin{array}{l}\text { Years after } \\
\text { reactor discharge }\end{array}$ & $\begin{array}{c}\text { Inner - Dose } \\
\text { Rate }[\mathrm{krad} / \mathrm{hr}]\end{array}$ & $\begin{array}{c}\text { Inner - Dose } \\
\text { Rate }[\mathrm{Gy} / \mathrm{s}]\end{array}$ & $\begin{array}{c}\text { Outer - Dose } \\
\text { Rate }[\mathrm{krad} / \mathrm{hr}]\end{array}$ & $\begin{array}{c}\text { Outer - Dose } \\
\text { Rate [Gy/s] }\end{array}$ \\
\hline 1 & 643 & 1.786 & 635 & 1.7639 \\
\hline
\end{tabular}




\begin{tabular}{|l|c|c|c|c|}
\hline 2 & 115 & 0.3194 & 108.1 & 0.3003 \\
\hline 5 & 46.1 & 0.1281 & 43.8 & 0.1217 \\
\hline 10 & 32.5 & 0.0903 & 32.1 & 0.089167 \\
\hline 25 & 21.8 & 0.0606 & 21.8 & 0.0606 \\
\hline 50 & 12.2 & 0.03389 & 12.2 & 0.03389 \\
\hline 100 & 3.82 & 0.01061 & 3.83 & 0.01064 \\
\hline
\end{tabular}

Table 8. Decay Heat for HFIR fuel in storage.

\begin{tabular}{|l|l|l|}
\hline Years after reactor discharge & HFIR Inner & HFIR outer \\
\hline 1 & 451 & 837.3 \\
\hline 2 & 152 & 280.3 \\
\hline 5 & 35.4 & 65.0 \\
\hline 10 & 22.0 & 40.7 \\
\hline 25 & 14.8 & 27.6 \\
\hline 50 & 8.2 & 15.2 \\
\hline 100 & 2.5 & 4.6 \\
\hline
\end{tabular}

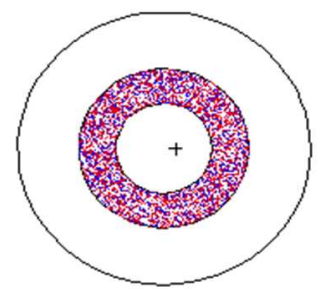

(a)

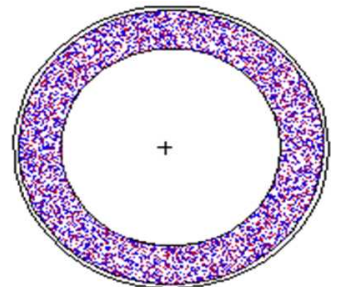

(b)

Figure 16. (a) Homogenized profile for DOE canister with HFIR inner assembly and (b) profile for HFIR outer assembly. 